\title{
Combining policy instruments for sustainable energy systems: An assessment with the GMM model ${ }^{\star}$
}

\author{
Peter Rafaj*, Leonardo Barreto and Socrates Kypreos \\ Energy Economics Group, Laboratory for Energy Systems Analysis, Paul Scherrer Institut, 5232 Villigen PSI, Switzerland \\ E-mail: peter.rafaj@psi.ch
}

\begin{abstract}
An assessment of the impact of an illustrative portfolio of policy instruments that address different sustainability concerns in the global energy system in areas of climate change, air pollution and introduction of renewable-energy resources is conducted. The effects of a policy set containing three instruments, implemented either individually or in combination, were examined. The policy instruments under examination in this work include: Cap-and-Trade policies imposing a $\mathrm{CO}_{2}$ emission reduction target on the global energy system, a renewable portfolio standard that forces a minimum share of renewable electricity generation, and the internalisation of external costs of power generation associated with local pollution. Implementation of these policy instruments significantly changes the structure and environmental performance of the energy sector, and particularly the structure of the electric-generation sector. The positive effects are amplified when the policy instruments are simultaneously applied, illustrating the potential for synergies between these energy-policy domains. The analysis has been conducted with the multi-regional, energy-system Global MARKAL Model (GMM), a "bottom-up" partial-equilibrium model that provides a detailed representation of energy technologies and endogenizes technology learning.
\end{abstract}

Keywords: impact assessment, combined policies, $\mathrm{CO}_{2}$ mitigation, renewable portfolio, externalities

\section{Introduction}

Driving the global energy system into a sustainable path is progressively becoming a major concern and policy objective $[1,2]$. The emergence of a sustainable global energy system, however, is a gradual long-term process requiring a profound transformation of its current structure. Addressing this multi-dimensional challenge requires a long-term systematic perspective and the integration of many different social, economic, environmental and technological elements.

In this context, it is relevant to examine the effects of policy measures that could contribute in the quest towards a sustainable global energy system and the role of advanced energy technologies in achieving this long-term goal. Impact assessment of policy instruments has become an important element of the policy development process. It represents a systematic attempt to shed light into the possible effects of policy proposals. As such, it serves as an aid to the decision-making process. Specifically, impact assessment plays an important role in the implementation of the sustainable-development strategies of the European Commission [3], among others.

A significant fraction of present $\mathrm{CO}_{2}$ emissions and air pollution originates from the combustion of fossil fuels to satisfy energy needs. Continuing along the current path of energy system development, and the anticipated rate of change attendant to that path, are not compatible with key

\footnotetext{
$\star$ A preliminary version of this paper has been presented at the 6th IAEE European Energy Conference on "Modelling in Energy Economics and Policy," 1-3 September 2004, ETH Zürich, Switzerland.

* Corresponding author.
}

elements of sustainability. Mitigation options in the energy system and associated costs, therefore, constitute a central point in the discussion of approaches to reducing adverse impacts and fossil fuels dependency. It is well recognized that the development and deployment of cleaner and more efficient energy technologies would have an important contributing role in facilitating the required emission reductions both in the short and long term (e.g., [4]). An important related question is the extent to which technologies can play this role, which policy instruments could foster their development and subsequent diffusion in the marketplace and how much would the implementation of those policies cost.

Policy instruments must be designed to encourage technological progress that enables a transition to a longterm sustainable path for the energy system. Related effects of these policies, therefore, must be examined not only in the light of short-term economic considerations (i.e., static efficiency), but also in terms of their long-run impacts (i.e., the so-called dynamic efficiency). One of the aspects of enhancing dynamic efficiency deals with the impact of the policy instruments on the ability of the energy system to achieve a transition in the long run towards a cleaner, more efficient, environmentally compatible and cost-effective technological path. Moreover, since the policy instruments typically targets a specific policy objective, it is important to examine the combined effects of several policy instruments, in order to identify potential synergies and/or trade-offs between them. A demonstration of cross-policy interaction in terms of environmental and cost impacts is particularly relevant for policymakers in regions where different sustainability issues have different 
immediate importance. For example, the local air pollution in China or South Asia is of a greater concern for local governments than curbing greenhouse gases (GHG) emissions [5].

Three different policy instruments, each of them addressing a different policy objective, i.e., (a) mitigation of climate change, (b) the promotion of renewable energy, and (c) reduction of local and transboundary air pollution, are adopted in the illustrative policy portfolio under examination in this paper. The policy instruments considered to address the above listed policy objectives (in the same order) are as follows: (a) a $\mathrm{CO}_{2}$ emissions reduction target in combination with international emissions trading, (b) a renewable portfolio standard in electricity generation, and (c) the internalization of external costs due to air pollutants in electricity generation technologies. These policy instruments are first analyzed separately. However, a policy instrument designed for a specific policy objective may affect other policy objectives as well. For example, a $\mathrm{CO}_{2}$ emissions reduction target may promote the introduction of renewable energy or lead to the introduction of electricity generation technologies with lower emissions of air pollutants. Under these circumstances, it makes sense to examine which are the impacts of a given policy instrument on several policy objectives, related to different policy areas. Therefore, selected combinations of policy instruments are considered herein and the potential for synergies is highlighted.

Although the discussion takes place in the context of the global energy system as a whole, emphasis is put on the global electricity sector given that, among others, the reduced number of actors and the relatively wide range of technology options as compared to other sectors make it likely to be one the main targets of sustainable-energy policies. The analysis has been conducted with the global, multiregional "bottom-up" energy-system Global MARKAL model (GMM) [6-8], which allows a detailed representation of energy technologies and endogenizes technology learning.

The remainder of this paper is organized as follows. Section 2 describes the energy-system GMM model used in this analysis. Section 3 presents the details of the portfolio of policy instruments under examination here and related relevant assumptions. Section 4 discusses selected results on the structural changes in the energy system due to the imposition of the policy measures and associated costs. Finally, section 5 outlines some conclusions. The mathematical formulation developed to implement the above policy measures in the GMM model is described in the Appendix.

\section{The modelling framework}

An effective assessment of energy-related policy instruments requires the use of models capable of simulating the technological change necessary to induce long-term, economic shifts towards a low-carbon global energy system(s), while simultaneously representing in adequate detail key energy-economy interactions. The latest version of GMM with endogenous technological learning (ETL) modelling capability, originally developed by Barreto [6], provides the basis of the results reported herein. As for any other MARKAL (Market Allocation)-type modelling exercises, these GMM-based analyses should also be considered prospective, with emphases placed on the trends and insights resulting from driving forces determined by implementing the respective policy options.

The GMM is a multi-regional, partial-equilibrium (i.e., only the energy sector is described), "bottom-up" (technology specific), energy-system model that allows a detailed representation of energy technology options on both demand and supply sides of the complete energy system for five world regions. Figure 1 gives a "top-level" depiction of the MARKAL energy flow and related technologies. The GMM version of MARKAL incorporates ETL with knowledge spillovers across world regions. Technological details at a level that is sufficient for addressing policy questions needed to understand the development of new technologies and subsequent deployment is an important attribute of GMM.

The five world regions described in GMM is shown in figure 2. Three regions represent the industrialized countries: North America (NAME) and the remaining countries that as of 1990 belonged to the OECD and designated as OOECD, which comprises Western Europe and the Pacific countries having OECD membership (Japan, Australia and New Zealand); the economies-in-transition region combines the Former Soviet Union and Eastern Europe (EEFSU). Finally, the developing countries are grouped into the two remaining regions: developing Asian countries are included in the region ASIA, comprising of centrally planned Asia, India, Southeast Asia and Pacific Asia; the rest of the world is incorporated into the region LAFM, which includes Latin America, Africa and the Middle East.

Six end-use energy demand sectors are described in GMM, as depicted in the right side of figure 1. Industrial and residential-commercial sectors are divided according to thermal and electric energy uses, which accounts for four of the six end-use demand sectors. The transportation sector merges passenger and freight transport sub-sectors. Finally, the non-commercial use of biomass and nonenergy feedstock is represented in the model. A set of generic end-use devices is defined for each of the demand sectors shown in figure 1. Assumptions concerning energyintensity and energy-demand projections for each region, and demand category are formulated according to trend extrapolations of past performance based on autonomously (e.g., not related to price) declining energy intensity together with considerations of regional income and price elasticities. The demand projections and potentials for fossil fuel and renewable-energy resources correspond to those characterized in the SRES-B2 storyline [10, 11]. The 


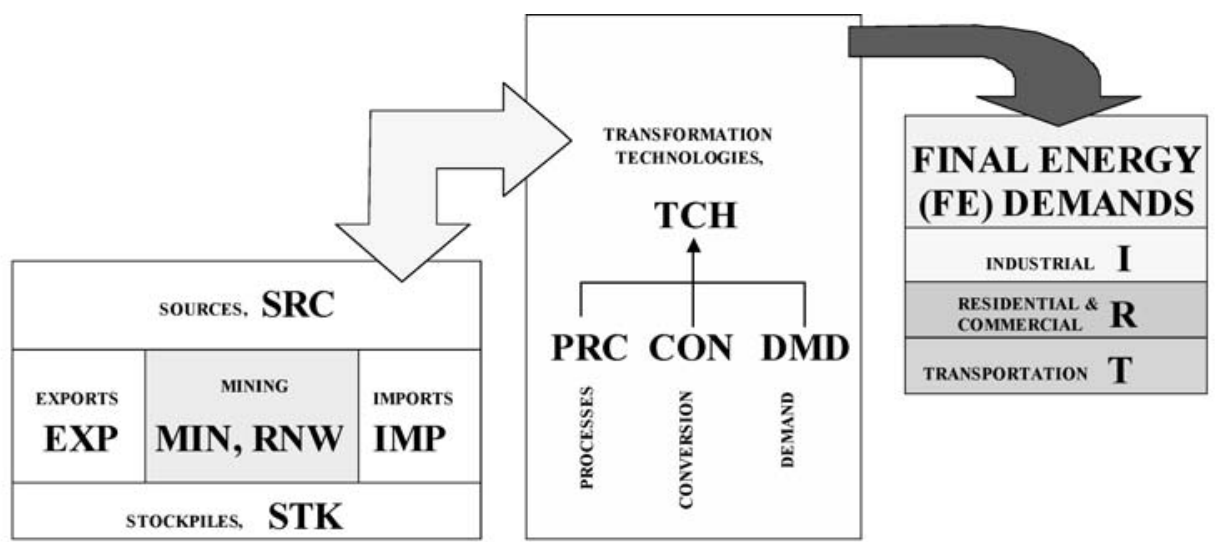

ENERGY FLOW: SOURCES $\square$ TRANSFORMATIONS $\square$ DEMANDS

MARKAL: SOURCES $\square$ TRANSFORMATIONS $\square$ DEMANDS

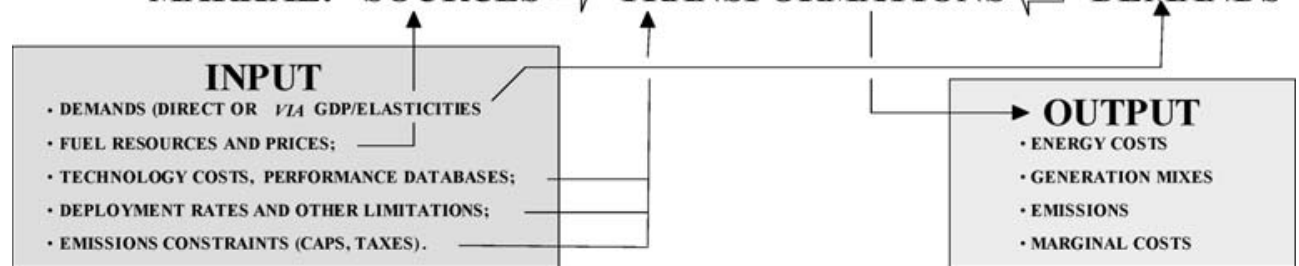

Figure 1. "Top-level" energy flows within MARKAL [9] showing the connectivity between sources, technologies, and demands, as well as typical input and outputs.

time horizon modelled in GMM is 2000-2050, while a discount rate of $5 \%$ per annum is used in all calculations.

Technologies for the production of electricity, heat, and a variety of final fuels (e.g., oil products, alcohol, hydrogen, natural gas), as derived from several fossil and non-fossil sources, are included, as well as the corresponding transmission and distribution chains. Capital investment, fixed operating and maintenance (O\&M), and variable O\&M costs are specified for all energy-supply technologies, with the former being endogenously determined for selected technologies as a function of installed capacity, according to the ETL algorithm used [12]; this procedure is elaborated in Appendix.

The details of mass and energy flows depicted for GMM at a "top level" in figure 1 differ little from the basic MARKAL model described by Fishbone and Abilock [9], and most recently by Loulou et al. [13]. In addition to the multi-regional characterization of global material and energy flows, important features of GMM include: (a) endogenous technological learning, (b) partial equilibrium, (c)

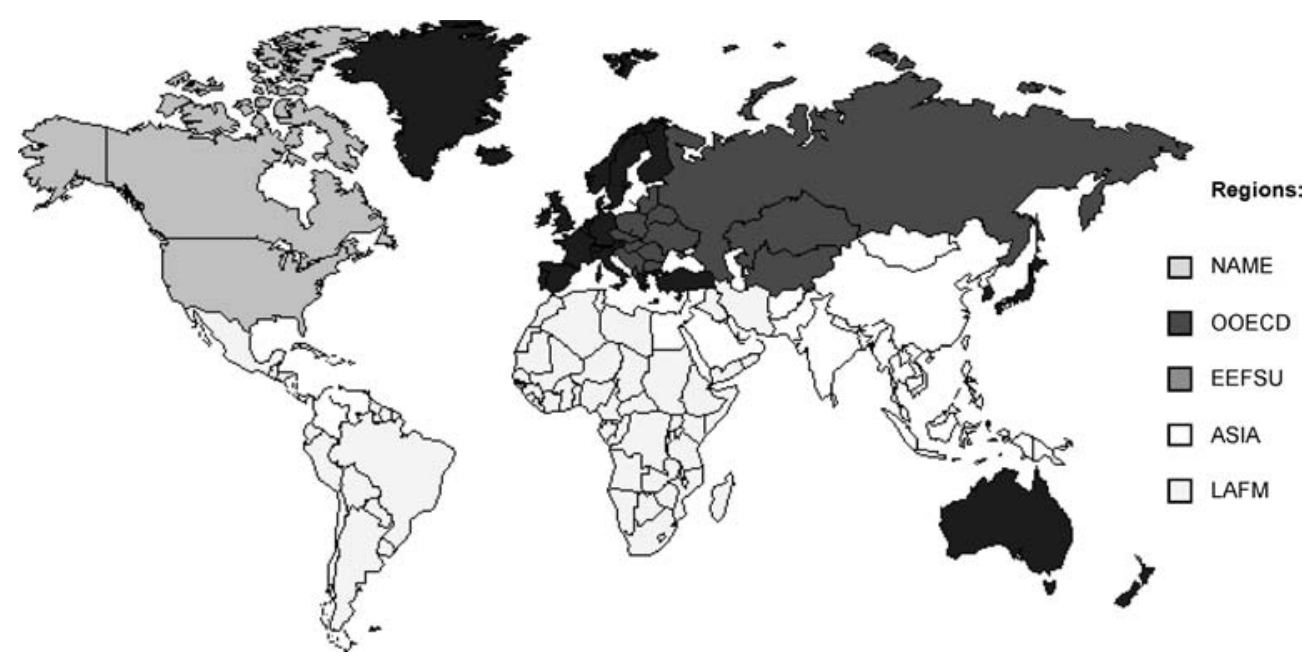

Figure 2. Definition of the five world regions in the GMM model. 
trade between regions. In the order listed, a brief paragraph on each of these three GMM capabilities is given below.

Endogenous technological learning. The GMM addresses technology dynamics in energy-systems models, and focuses on understanding the impacts of ETL, which can be a key driving force behind technological progress [14]. A typical learning curve describes the decrease in the specific (unit) cost of a given technology as a function of the cumulative installed and operating capacity, which serves as a proxy for the accumulated experience. This approach reflects the fact that some technologies can experience declining unit costs because of the process of 'learning-by-doing' (LBD). ETL enables analysis of the way in which respective technology enters the energy market through learning-induced unit-cost reductions. In the version of the GMM model used in this analysis, technology learning is endogenized only for the investment costs of selected electricity generation technologies, summarized in table 1 together with the corresponding learning rates (LR) and initial specific investment costs. The learning rates assumed here are within the ranges reported in the literature [15]. The investment costs are given in US dollars of the year 2000 .

Partial equilibrium. The GMM version used for this analysis applies the ETL option in combination with a partial equilibrium algorithm [16] that adjusts demands for energy services to the changes (increases) in marginal cost of services that results from the imposition of a given policy constraint, as described below. The energy end-use demands that drive GMM are elastic to the own prices, which are endogenously computed by the model in the Baseline case; these demands are self-adjusted if modifications related to a given non-Baseline scenario affect prices. The model obtains equilibrium when the sum of producer and consumer surpluses is maximised. Consequently, the model

Table 1

Electricity generation technologies for which technology learning is endogenized in this analysis together with learning rates and initial specific investment costs.

\begin{tabular}{lcc}
\hline Technology & $\begin{array}{c}\text { Learning } \\
\text { rate }(\%)\end{array}$ & $\begin{array}{c}\text { Initial specific investment } \\
\text { cost }\left(\mathrm{US}_{2000} / \mathrm{kW}\right)\end{array}$ \\
\hline Hydrogen fuel cell & 18 & 3,500 \\
Advanced coal plant & 6 & 1,584 \\
Advanced coal plant with & 7 & 2,060 \\
$\mathrm{CO}_{2}$ capture & & \\
IGCC & 6 & 1,401 \\
IGCC with $\mathrm{CO}_{2}$ capture & 7 & 1,910 \\
New nuclear power plant & 4 & 1,900 \\
Gas combined cycle & 10 & 560 \\
Gas combined cycle with & 10 & 1,015 \\
CO ${ }_{2}$ capture & & 2,463 \\
Gas fuel cell & 18 & 5,000 \\
Solar photovoltaics & 19 & 1,150 \\
Wind turbine & 10 & \\
\hline
\end{tabular}

Learning rate (LR) is defined as the relative decrease in specific investment cost upon doubling of the installed capacity. objective function comprises two terms: the energy/technology production costs and the loss of consumers' welfare associated with demand reduction [17].

Trade between regions. The GMM also allows simulation of bilateral and global trade of selected energy or environmental commodities (e.g., fuels, electricity, emission permits). Global trade of any given commodity must balance at each period (i.e., the sum of trade variables over all regions is equal to zero). The quantities as well as the unit cost (corresponding to the marginal price) of an endogenously traded commodity are model results. Marginal price of the commodity globally traded among regions reflects the cost that the energy system incurs for a unit of trade [13].

\section{Portfolio of policy instruments}

The illustrative policy portfolio analyzed in this study comprises three main policy instruments in the areas of climate-change mitigation, internalisation of externalities due to local pollutants in the electricity generation sector, and the promotion of renewable-based electricity generation as follows:

- $\mathrm{CO}_{2}$ emission reduction target - "Soft landing" scenario: This policy element adopts a Kyoto-like [18] scenario for $\mathrm{CO}_{2}$ mitigation by forcing in the long term a "cap-and-trade" scheme across all world regions, all energy sectors, and all electricity generation technologies to stabilise global carbon emissions. The mechanism for distributing emission permits among regions takes into account the needs and aims of economic development in non-Annex B countries.

- Renewable portfolio scheme: The second element of the policy set used in this analysis considers options and addresses the impacts of imposing an obligation to generate an exogenously determined, minimum amount of renewable electricity in all world regions. Trading of so-called "green certificates" between world regions is foreseen under this minimum-renewable-generation constraint, wherein this trade would occur between regions having surpluses renewable electricity and those having limited or expensive renewable-energy options for power generation; this policy element represents a kind of "cap-and-trade" policy that favours renewable resources.

- Internalisation of external costs: The third element of the policy set examines implementation of measures that internalise the external costs of power generation related to air pollution $\left(\mathrm{SO}_{2}, \mathrm{NO}_{x}, \mathrm{PM}\right)$. Herein, external costs are charged for the each electricity production technology and are estimated by applying the ExternE-Project costs determined for Europe [19] to all world regions, after adjusting costs for regional differences in population density, fuel quality, power-plant 
thermal efficiency and application of emissions-control systems.

Additionally, the impacts of applying selected combinations of policy elements within this policy set are examined in Combined policy scenarios: Soft landing + Renewable portfolio; Soft landing + External Costs; Renewable portfolio + External Costs; Soft landing + Renewable portfolio + External Costs. In this section, a description of the policy instruments and related assumptions in the cases analysed here is presented.

Implicit in all different policy options discussed above is the stimulation of endogenous technology learning (ETL) via learning investments that help advanced, carbon-free technologies to progress along learning curves. Support of such initially more costly technologies is important to avoid "lock-outs" of new and promising technologies that are not yet able to successfully compete in the energy markets against the established, conventional technologies based largely on burning fossil fuels. All policy elements listed above, therefore, are analysed with active ETL option, and, in the case of the Soft landing scenario, the results are contrasted with case where the option for ETL is inactive. Finally, additional modalities (e.g., cumulative emission constraint, trade exclusion) of the Soft landing scenario are examined in section 4 .

The set of policy instruments used in this study is applied on a baseline development scenario based on the B2 scenario reported by Intergovernmental Panel on Climate Change (IPCC) [10]. The B2 storyline envisages a given degree of increased concern for environmental and social aspects and is consistent with current institutional frameworks and current technology dynamics. Population growth is consistent with the United Nations median projection for population growth, which is projected to increase to 9.4 billion people by the year 2050, and follows a continuation of historical trends. Economic growth is gradual, with the world gross domestic product (GDP) increasing at an average rate of $2.8 \%$ per annum between 2000 and 2050 . Income per capita is projected to grow at a globally average rate of $1.8 \%$ per year for the same period, which translates into an average value of $11,700 \$_{(1990)}$ per capita in the year 2050 at market exchange rates.

\section{1. $\mathrm{CO}_{2}$ emission reduction target - "Soft landing" scenario}

In the Soft landing scenario, a carbon-constrained world is assumed, wherein global, but smooth, carbon emission reduction commitments towards an emission target of $10 \mathrm{GtC} / \mathrm{yr}$ (Gigatonnes carbon $-10^{9}$ tonne per year) by the year 2050 are specified, as shown in table 2. Each GMM region applies its specific $\mathrm{CO}_{2}$ reduction entitlement, contributes to the global carbon reduction effort, and simultaneously trades carbon emission permits to meet these goals. The carbon emissions targets for each of the five world regions are defined such that the $\mathrm{CO}_{2}$ concentrations are stabilized in the long term at about 550 ppmv (parts per million by volume) of atmospheric $\mathrm{CO}_{2}$. The 550-ppmv concentration target is frequently used as a precautionary, but attainable, level and represents the middle value of stabilisation level identified by Wigley et al. [20]. The allocation of emission entitlements takes into consideration the aspirations of lessdeveloped countries for economic growth and distributes total emissions such that a smooth trajectory to $10 \mathrm{GtC} / \mathrm{yr}$ will be obtained before 2050, followed by a subsequent decline.

Specific rules are applied to define regional $(r) \mathrm{CO}_{2}-$ emission reduction entitlements. For the Annex B countries (AB), the emission reduction rate $\left(K_{r r}\right)$ is the same as established in the Kyoto protocol for the first commitment period 1990-2010. For example, if the reduction target for the EU in 2010 is $8 \%$ below 1990, its carbon emissions (CEM) in 2030 should not exceed $0.92 * 0.92$ times its emission levels in 1990:

$$
\begin{aligned}
& \mathrm{CEM}_{\mathrm{EU}, 2030} \leq \mathrm{CEM}_{\mathrm{EU}, 1990} \times\left(1-K_{r r_{\mathrm{EU}}}\right)\left(1-K_{r r_{\mathrm{EU}}}\right), \\
& \text { while } \mathrm{EU} \in \mathrm{AB}
\end{aligned}
$$

This rule, however, does not apply for setting carbon constraints to developing countries. The original Soft landing scenario, as described by Blanchard et al. [21], proposes linearly reducing the emissions growth rates for developing countries at different horizons, taking into account their per capita GDP, per capita carbon dioxide emissions, and population growth rates. Because of the high regional aggregation of GMM, the same method for the allocation of $\mathrm{CO}_{2}$ entitlements in the non-Annex $\mathrm{B}$ countries (NAB) was not used in this exercise, but was approximated by the assumption, that by $\sim 2030$ the growth in $\mathrm{CO}_{2}$ emissions from developing regions ASIA and LAFM must be at most equal to the reduction of the Annex B countries based on the extension of the Kyoto protocol until 2050. This means, the developing regions have to stabilise the carbon emissions

Table 2

Carbon-emission reduction target in the Soft landing scenario.

\begin{tabular}{lcrrrr}
\hline Year & 2000 & 2010 & 2020 & 2030 & 2040 \\
\hline Global carbon emission target (GtC/yr) & n.a. & $7.7^{\text {a }}$ & 8.6 & 9.4 & 10.0 \\
Reduction over Baseline (\%) & 0.0 & -5.7 & -12.8 & -22.4 & -31.3 \\
\hline
\end{tabular}

${ }^{\mathrm{a}}$ In 2010, only OOECD and EEFSU regions are committed to reduce $\mathrm{CO}_{2}$ emissions. 
over the reference development (REF) but significantly later as compared to the Annex B countries:

$$
\Delta \mathrm{CEM}_{\mathrm{NAB}, t}=\mathrm{CEM}_{\mathrm{NAB}, t}^{\mathrm{REF}}-\mathrm{CEM}_{\mathrm{NAB}, t} \leq \mathrm{fr}_{\mathrm{AB}, t}
$$

where the term $\mathrm{fr}_{\mathrm{AB}, t}$ stands for the fractional reduction of $\mathrm{CO}_{2}$ emissions below the reference case in the Annex $\mathrm{B}$ regions (see Appendix). To achieve a stabilisation of carbon concentrations, the global emissions and those of the non-Annex B countries should, in the longer term, stabilise and eventually decrease, according to:

$\sum_{r} \mathrm{CEM}_{t}=\mathrm{CEM}_{\mathrm{AB}, t}+\mathrm{CEM}_{\mathrm{NAB}, t}$, and $\sum_{r} \mathrm{CEM}_{2050}<10 G t C$

An example of different rules for allocation of emission entitlements proposed in order to share the burden of global $\mathrm{CO}_{2}$ mitigation while taking into consideration the international equity aspects can be found in, e.g., Miketa and Schrattenholzer [28].

Alternative approaches for setting $\mathrm{CO}_{2}$ targets are examined herein by using a cumulative carbon emission constraint. Instead of imposing annually fixed emissions limits for each time period, a cumulative $\mathrm{CO}_{2}$ constraint for the whole commitment period is specified equal to the integral of the annual bounds associated with the Soft landing scenario. Simultaneously, trade of carbon permits between regions is allowed. Optimising under these conditions allows for the "when" and "where" flexibility options in carbon mitigation policies, which promise the maximum possible efficiency in meeting carbon constraint specifications.

\subsection{Renewable portfolio scheme}

A policy of imposing an obligation to generate certain fraction of renewable electricity (also called Renewable portfolio standard) forces the power suppliers to include a minimum share of renewable energy into the supply mix. Because of technological, natural and economic limitations, the renewable electricity target can often be achieved in a more efficient way by the introduction of a green certificates trading system. In this case, the green certificates serve as a commodity that represents electricity generated from renewable-energy sources. This commodity

Table 3

Relative share of renewable electricity forced by the Renewable portfolio scheme scenario.

\begin{tabular}{lcccccc}
\hline $\begin{array}{l}\text { Relative share of } \\
\text { renewable power } \\
\text { generation (\%) }\end{array}$ & 2000 & 2010 & 2020 & 2030 & 2040 & 2050 \\
\hline OOECD, EEFSU & n.a. & 18 & 23.5 & 28 & 31.5 & 35 \\
NAME & n.a. & 15 & 23.5 & 28 & 31.5 & 35 \\
ASIA, LAFM & n.a. & n.a. & 23.5 & 28 & 31.5 & 35 \\
\hline
\end{tabular}

is traded (on a regional or local level) between countries/ regions with surpluses of generated renewable power and those having limited or expensive possibilities to produce renewable power [22].

The scenario presented in this work forces the renewable electricity sources (including large hydropower) to contribute in each region to the total electricity generation by $35 \%$ in $2050 .{ }^{1}$ Industrialised countries start to fulfil the policy target in 2010 (respecting the present EU policies), and the developing regions of ASIA and LAFM start to apply the Renewable portfolio scheme in 2020, according to the scheme summarized in table 3 . Since the green certificates are traded among all regions to allocate the investments to the region that offers the most efficient options in producing renewable electricity, the model identifies the same marginal cost of green certificates per region and time. As a first approximation, zero transaction costs are assumed. The large market penetration rate for renewable electricity, as imposed in this study, might go beyond the limits of electricity network stability and its manageability to secure the load profile. In this case, high penetration rates should be followed by renewable sources with back up by fossil-fuel systems. Potential effects of fossil back-up systems were not analysed in this exercise. Power network stability aspects are taken into account by assuming a maximum penetration fraction of intermittent power generation (e.g., wind power, solar photovoltaic) of $25 \%$ of total production.

\subsection{Internalisation of external costs}

An external cost of electricity is introduced if the emissions generated by power plants imply damages to the society and the invoked cost is not a part of the market price of electricity. Usually, the production cost per unit of electricity is expressed as function of the capital cost, the fixed and variable O\&M cost, and the fuel cost. Internalisation of external costs intends to compensate for the health and environmental damage and thereby yields a fullcost pricing of electricity. These extra charges per unit of $\mathrm{kWh}$ generated by region and technology are included in the total electricity generation cost, as well as in the total energy system cost (see Appendix).

Values for external cost used in this study are based on the results from the European Commission (EC) ExternE Project [19]. The methodology used in the ExternE Project applies an approach based on impact pathway, wherein the pathways of polluting substances are followed from the release source to the point where damage occurs. The consecutive negative impacts (damage) are quantified using damage functions, which relate cost to cumulative

\footnotetext{
${ }^{1}$ Different scenario analyses evaluate the potential contribution of renewable energy sources to the global supplies to be within a range between 20 and $50 \%$ after 2050 [23]. The target specified in this study correlates closely with minimum shares of renewables assumed for 550ppm scenario of DNE21 model [24].
} 
Table 4

Basic assumptions made for the external cost calculation.

\begin{tabular}{llcc}
\hline Region & $\begin{array}{c}\text { Population } \\
\text { density }\end{array}$ & $\begin{array}{c}\text { Sulphur content } \\
\text { in coal }(\%)\end{array}$ & $\begin{array}{c}\text { Starting year of } \\
\text { externality charges }\end{array}$ \\
\hline NAME & Medium & 1 & 2010 \\
OOECD & High & 1 & 2010 \\
EEFSU & Medium & 1 & 2010 \\
ASIA & High & 1 & 2010 \\
LAFM & Medium & 1 & 2010 \\
\hline
\end{tabular}

emissions. Economic valuation of the damage is determined by the "willingness-to-pay" for the affected individual to avoid a negative impact resulting from energy production from a given power plant. This "bottom-up" approach emphasizes detailed site-specific characterization of technologies, and considers all important stages in different energy chains and comparisons between different fuel cycles and different types of burden and impact within a fuel cycle.

For the purpose of internalisation of the external cost of the local pollution $\left(\mathrm{SO}_{2}, \mathrm{NO}_{x}, \mathrm{PM}\right)$ within the total electricity cost for different technologies in different world regions, the ExternE results had to be adjusted to reflect the GMM level of aggregation. The determinants for scaling the externalities were the population density in regions; fuel quality expressed as the content of the sulphur in coal and oil; technology specification with respect to installation of the emissions control systems; and finally, the possible improvement in conversion efficiency of the power generating systems over the modelled time horizon [24]. External costs associated with emissions of GHGs are not considered in this study. It is important to add that this analysis is not intended to provide detailed estimates of external costs in different world regions, which are highly dependent on local conditions and uncertain for a number of developing regions. Instead, the case of policies addressing externalities together with the two policy tools described above is used to examine the effects of a combination of policy instruments addressing sustainability concerns in the global energy system.

Table 4 summarises basic assumptions made for the adjustment of external cost. The world regions are grouped in two population density categories according to present statistical data [25]. The ASIA and OOECD regions are located within the category of High density of population, and the remaining regions are assumed to have Medium population density. Changes in population density with time are not considered. Sulphur content in coal is assumed to be $1 \%$ in all world regions. A literature survey indicates that this value represents the typical average of all different coal types used for power production (see, e.g., Hinrichs [26]).

External costs were further scaled as a function of conversion efficiency so that exogenously given efficiency improvements could be taken into account. The resulting external costs are displayed in table 5. Ranges in the values of external cost represent regional differences resulting from assumptions and scaling, as explained above.

\subsection{Combined policy scenarios}

When the (three) policy elements defined above are applied simultaneously or in combination, possible tradeoffs and synergies can emerge in terms of cost and environmental impacts. It is important to examine these effects of combined policy instruments in several grounds. Policymakers are more likely to use a policy mix using a range of policy instruments rather than isolated measures. Therefore, it is essential to examine the presence of synergies and/or trade-offs between policy instruments addressing different policy domains. Synergies occur when actions are common to two or more policy objectives. A trade-off occurs when the best way to achieve two or more policy objectives is very different. When synergies exist, the costs of combined policies may be lower than the costs of separate policies. The following combinations of single policy options are examined:

- Soft landing + Renewable portfolio;

- Soft landing + External Costs;

- Renewable portfolio + External Costs;

- Soft landing + Renewable portfolio + External Costs.

In principle, a large number of scenario permutations are possible. For instance, if the policy instruments above

Table 5

External cost for power generation technologies represented in the GMM model.

\begin{tabular}{|c|c|}
\hline Technology & $\begin{array}{l}\text { External costs } \\
(\notin / \mathrm{kWh})\end{array}$ \\
\hline \multicolumn{2}{|l|}{ Fossil fuel-based power plants } \\
\hline Coal conventional electric & $8.8-20.6$ \\
\hline Coal conventional electric with $\mathrm{DeSO}_{x} / \mathrm{DeNO}_{x}$ & $1.3-1.9$ \\
\hline Coal conv. with $\mathrm{DeSO}_{x} / \mathrm{DeNO}_{x}$ and $\mathrm{CO}_{2}$ capt. & $1.6-2.5$ \\
\hline Coal advanced electric (Supercritical, PFBC ${ }^{\mathrm{a}}$ ) & $1.7-2.6$ \\
\hline Coal advanced electric with $\mathrm{CO}_{2}$ capture & $2.0-3.1$ \\
\hline $\begin{array}{l}\text { Integrated coal gasification combined } \\
\text { cycle (IGCC) }\end{array}$ & $0.6-1.1$ \\
\hline Coal IGCC with $\mathrm{CO}_{2}$ capture & $0.7-1.3$ \\
\hline Natural gas combined cycle (NGCC) & $0.3-1.2$ \\
\hline NGCC with $\mathrm{CO}_{2}$ capture & $0.3-1.4$ \\
\hline Gas turbine & $1.3-1.8$ \\
\hline Gas steam conventional & $1.2-3.2$ \\
\hline Co-generation gas turbine & $1.4-1.9$ \\
\hline Gas fuel cell (FC) & 0.3 \\
\hline Hydrogen fuel cell (FC) in industry & 0.3 \\
\hline Hydrogen fuel cell (FC) in res\&com. & 0.3 \\
\hline Oil electric & $1.4-6.4$ \\
\hline \multicolumn{2}{|l|}{ Nuclear and renewable-energy power plants } \\
\hline Nuclear plant - Light Water Reactor (LWR) & 0.5 \\
\hline Advanced new nuclear power plant (NNU) & 0.5 \\
\hline Hydro-electric plant & 0.1 \\
\hline Solar photovoltaic (SPV) & 0.1 \\
\hline Solar thermal electric & 0.1 \\
\hline Wind turbine & 0.1 \\
\hline Biomass power plant & 0.3 \\
\hline Geothermal electric & 0.15 \\
\hline
\end{tabular}

${ }^{\text {a }}$ Pressurised Fluidised Bed Combustion. 
Table 6

Scenarios specifications and description.

\begin{tabular}{ll}
\hline Scenario name & \multicolumn{1}{c}{ Scenario specification } \\
\hline Baseline & $\begin{array}{l}\text { Baseline case, No policy constraint, } \\
\text { No-Trade of emissions permits, with ETL }\end{array}$ \\
\hline $\begin{array}{l}\text { Single policies } \\
\text { Soft landing }\end{array}$ & Carbon constraint, Partial equilibrium, \\
Trade of emissions permits, ETL \\
Renewable portfolio & $\begin{array}{l}\text { Penewable-electricity share constraint, } \\
\text { certificates, ETL }\end{array}$ \\
& External costs from local pollutants, \\
Externalities & Partial equilibrium, No-Trade of \\
& emissions permits, ETL
\end{tabular}

Combined policies Soft landing + Renewable portfolio

Soft landing + Externalities

Renewable portfolio + Externalities

Soft landing + Renewable portfolio + Externalities
Carbon constraint, Trade of emissions permits, Renewable-electricity share constraint, Trade of green certificates, Partial equilibrium, ETL

Carbon constraint, Trade of emissions permits, External costs from local pollutants, Partial equilibrium, ETL Renewable-electricity share constraint, Trade of green certificates, External costs from local pollutants, Partial equilibrium, ETL

Carbon constraint, Trade of emissions permits, Renewable-electricity share constraint, Trade of green certificates, External costs from local pollutants, Partial equilibrium, ETL time horizon and is largely dominated by fossil fuels, as is indicated by figure 3 . Use of both coal and natural gas grows substantially, with clean-coal technology and natural gas becoming the predominant sources of electricity by the end of the 2050 time horizon. Growth of oil remains modest, but it continues to make a significant contribution to primary-energy demand. Non-fossil resources slowly gain market share. ${ }^{2}$

A significant increase in non-fossil sources is observed in the Soft landing scenario, where contribution of nuclear energy doubles and renewables increase their share by $25 \%$ by 2050 over the Baseline. By the end of the time horizon consumption of coal is reduced by $50 \%$ when compared to the reference case. Natural gas consumption remains at the same level, and reductions in oil use occur to a lower extent.

In the case of the Renewable portfolio scheme imposed on the Baseline, the contribution of renewables reaches more than $25 \%$ of the global primary-energy consumption in 2050. Renewables substitute for other fuels, particularly for coal and nuclear energy, where reduction of 20 and $23 \%$ relative to the Baseline is observed.

Internalisation of external costs from local pollution in the power sector leads again to a strong reduction in coal consumption, but this reduction is substantially larger during the period 2010-2030 in comparison to other policy scenarios. Coal is replaced primarily by nuclear energy, and the rapid reduction in coal use is balanced with rising use of natural gas, oil and renewable power.

\subsection{Electricity generation}

Electricity generation experiences a vigorous growth in the Baseline scenario with the bulk of this growth driven by developing regions. Coal-fired power plants dominate the electricity market with increasing share of advanced technologies [pressurised fluidised bed combustion (PFBC), integrated coal gasification combined cycle (IGCC)]. The gas combined cycle, as well as wind turbines, experience significant growth. The contribution from nuclear power does not grow substantially, but a substitution of conventional plants by new reactor designs takes place. The amount of hydroelectric production grows only slightly. Solar photovoltaic remains in essence "locked-out."

For the Soft landing scenario, the $\mathrm{CO}_{2}$ emissions reduction target is primarily achieved by a strong reduction ( $-48 \%$ compared to the Baseline scenario) of coal combustion for power production, as shown in figure 4 . The only coal-based technology that undergoes significant increase compared to the Baseline scenario is IGCC with carbon capture and sequestration. Generation systems based

\footnotetext{
2 The fossil-fuel equivalent for these non-fossil sources is taken as the reciprocal of the average efficiency of the fossil fuel power plants, and is used for reporting the primary-energy equivalent of renewable and nuclear energy production of electricity. A fossil equivalent of 3.033 is used in GMM.
}

Under the Baseline scenario, global primary-energy consumption experiences a significant increase over the 


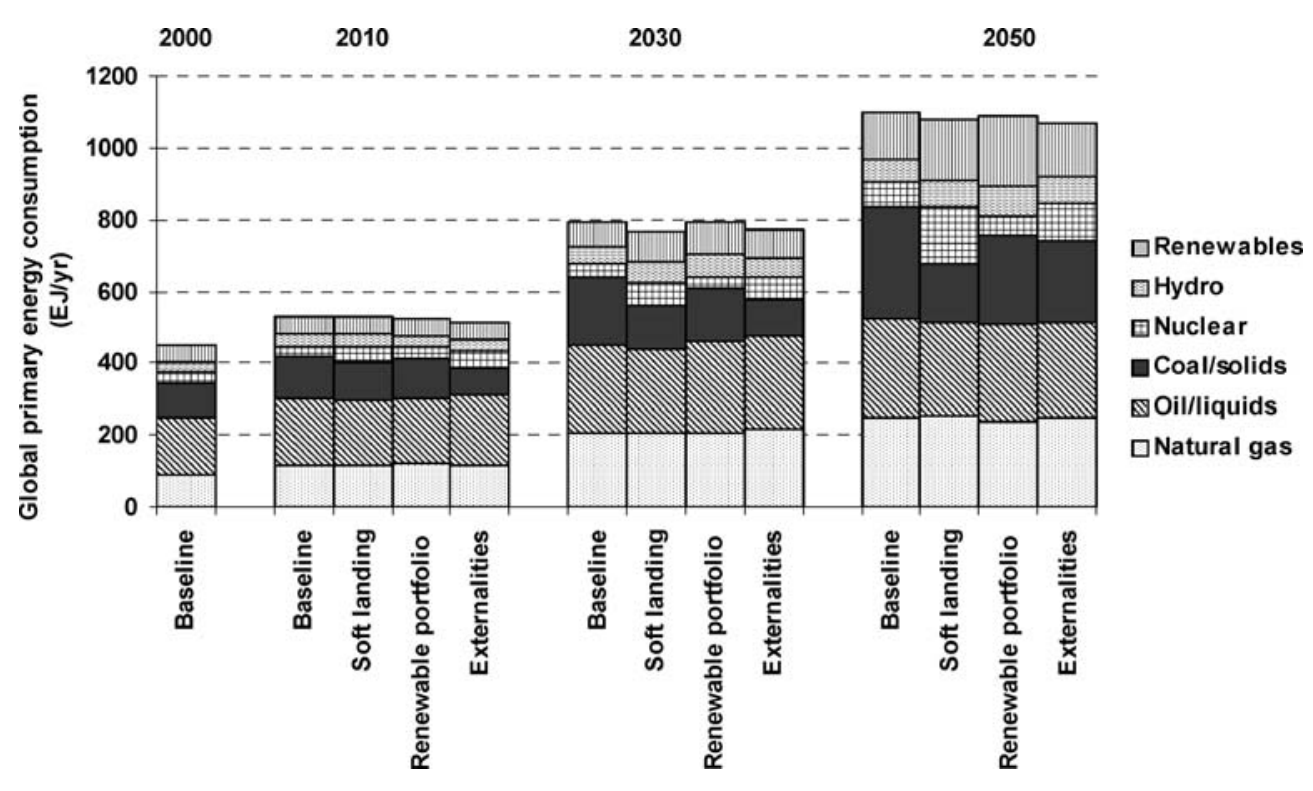

Figure 3. Global primary energy use for the Baseline and policy scenarios investigated.

on natural gas combined cycles (NGCC) become the main source of electricity by the end of the time horizon, followed by nuclear power. Natural gas and nuclear power together account for one half of the total electricity production in 2050. Renewable electricity sources increase their contribution by $21 \%$ as compared to the Baseline scenario.

Renewable portfolio policies force the share of renewable electricity to achieve levels specified in table 3. Electricity generation from fossil-based technologies is steadily reduced over the time horizon. Both coal- and gas-based generation is affected, and the total contribution of the fossil sources in 2050 is lowered by $25 \%$ relative to the
Baseline. The role of nuclear energy in the electricity market is also reduced, especially in the last time period, with this decrease occurring mainly because of decelerated learning effect for advanced nuclear systems.

Internalising the external costs of local pollution into electricity production cost significantly influences the structure of the power generation mix. Coal remains the major contributor to total power production, although its share is reduced in 2030 by $55 \%$ and in 2050 by $27 \%$ relative to the Baseline. Moreover, the conventional pulverised coal combustion is replaced by systems with $\mathrm{SO}_{2}$ and $\mathrm{NO}_{x}$ emissions control and by advanced coal (i.e.,

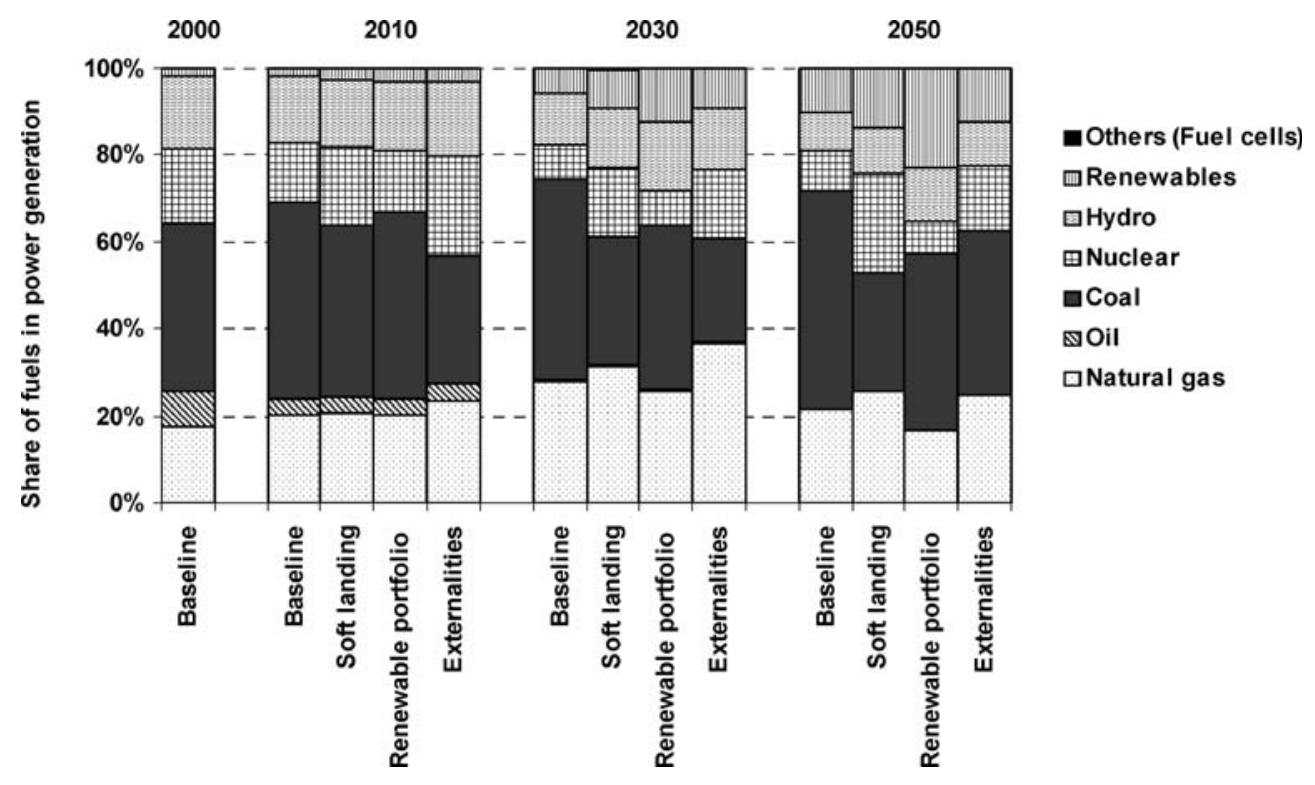

Figure 4. Development in the global electricity production by fuel (relative shares). 
Table 7

Increase in average shadow price of electricity in policy scenarios relative to the Baseline.

\begin{tabular}{lccrr}
\hline Scenario & $2010(\phi / \mathrm{kWh})$ & $2020(\varnothing / \mathrm{kWh})$ & $2030(\phi / \mathrm{kWh})$ & $2040(\varnothing / \mathrm{kWh})$ \\
\hline Soft landing & $0.4(7 \%)$ & $0.5(11 \%)$ & $0.5(13 \%)$ & $1.4(35 \%)$ \\
Renewable portfolio & $0.1(2 \%)$ & $0.4(7 \%)$ & $1.0(25 \%)$ & $1.6(37 \%)$ \\
Externalities & $3.1(67 \%)$ & $2.5(48 \%)$ & $1.0(26 \%)$ & $1.7(40 \%)$ \\
\hline
\end{tabular}

supercritical plants, PFBC, IGCC). The NGCC plants and other natural-gas-based systems increase their share in power production to a level of $37 \%$ and $25 \%$ of the total electricity supply in 2030 and 2050, respectively. Finally, the share of renewables and nuclear plants in 2050 is increased by $28 \%$ relative to the Baseline case because of lower external costs charged to these systems.

All policies imposed on the Reference Energy System (RES) reduce the overall power generation, since the production cost of electricity increases. The largest decrease in electricity production in 2050 relative to the Baseline is observed in the Renewable portfolio case $(-5.6 \%)$, while internalising externalities from local pollutants reduces total power generation by a smaller degree $(-3.6 \%)$. This result is an indication of the severity of the policy options analysed and suggests that, under conditions of forced share of electricity generated from renewable-energy sources, the induced electricity price increase results in electricity demand reductions and substitution of electricity for other fuels by the end users. Table 7 summarises the increase in average shadow price of electricity over the Baseline for all three policy scenarios under investigation.

Figure 5 illustrates the power generation profile in 2050 for the Baseline and three single-policy scenarios considered in this study. In the Soft landing scenario, the coalbased generation is displaced in favour of natural gas
(NGCC), renewables (including hydropower) and, above all, nuclear power plants. Advanced coal technologies (PFBC, IGCC) with $\mathrm{CO}_{2}$ capture, however, penetrate the market at a significant level. Targets prescribed under the Renewable portfolio scheme are achieved by a significant increase in electricity generation from biomass, hydropower, geothermal sources, as well as from solar photovoltaic systems (SPV). Growth in generation from wind turbines is not substantial, as this technology is already approaching its technical potential in the Baseline. This scenario is the only one where SPV gain a market share in 2050. Increases in renewable electricity generation are balanced by reductions from NGCC, coal plants and advanced nuclear systems. The main impact of the internalisation of external costs on the power sector is the massive elimination of generation from conventional coal power plants, and the accelerated market penetration of advanced systems with low $\mathrm{SO}_{2} / \mathrm{NO}_{x}$ emissions rates. Additionally, low external cost increases the competitiveness of nuclear power plants and renewables compared to the Baseline.

Findings from this study suggest that nuclear power and the advanced coal technologies with $\mathrm{SO}_{2} / \mathrm{NO}_{x}$ control operated in combination with plants with carbon-removal constitute an attractive technological mix towards carbon and local pollution mitigation strategies for the time horizon investigated.

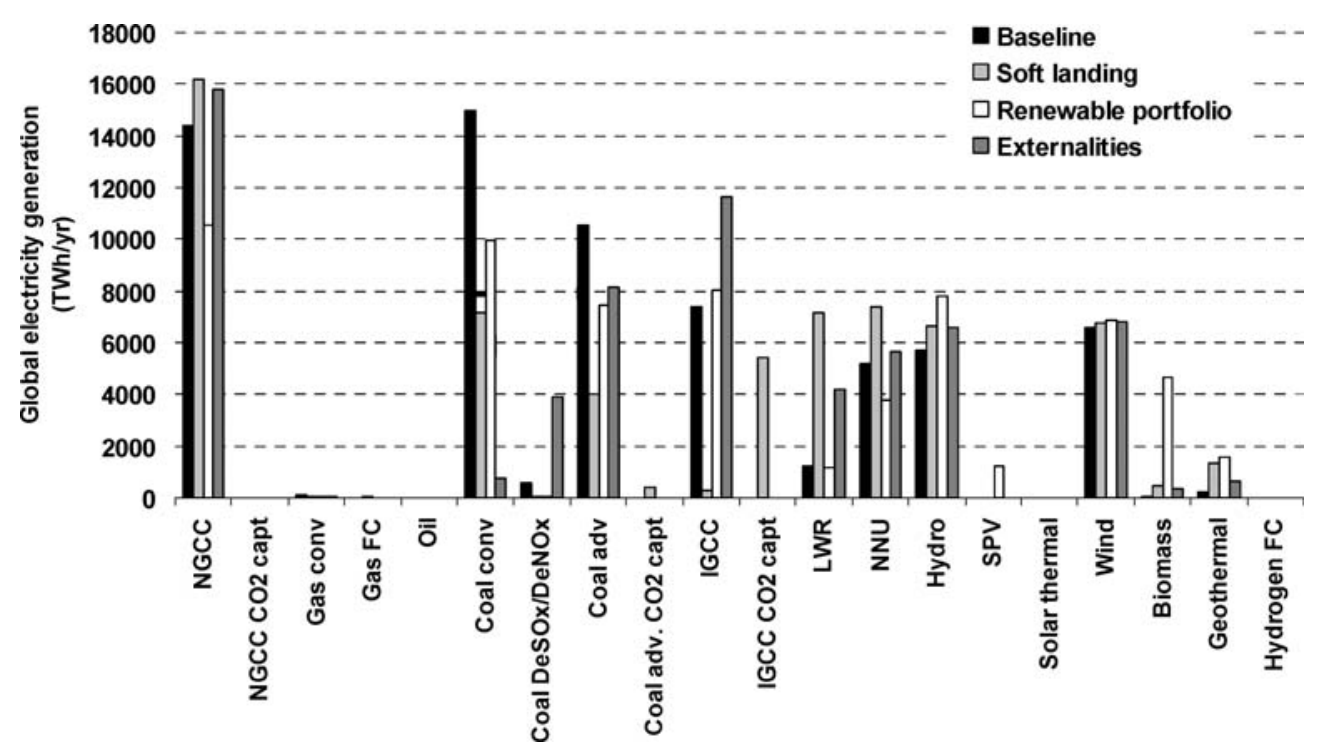

Figure 5. Contributions of different technologies to the global electricity generation mix in 2050. For nomenclature, see table 4. 


\subsection{Global $\mathrm{CO}_{2}$ emissions}

Total global carbon emission rates in the Baseline scenario increase continuously throughout the time horizon modelled, giving an annual rate of $1.97 \% / \mathrm{yr}$ and reaching a level of $16.8 \mathrm{GtC} / \mathrm{yr}$ by the year 2050 . A common effect of the three policy instruments under study is the reduction of $\mathrm{CO}_{2}$ emissions as compared to the development in the Baseline. The extent of the policy-induced carbon mitigation depends on the particular policy tool being implemented, on the deployment of the carbon-control technologies (e.g., renewable energy or nuclear energy versus $\mathrm{CO}_{2}$ capture), and on the timing and effectiveness of the respective policy implementation in different world regions. Furthermore, various cross-policy interactions contribute to the decarbonisation effects of policies adopted concurrently.

Under the Soft landing carbon constraint, emission growth is strongest around 2020, while a stabilisation trajectory begins after 2030 to reach the level below 10 $\mathrm{GtC} / \mathrm{yr}$ by 2050 . The global carbon emissions decrease over the Baseline scenario by $41 \%$ in 2050 and represent an absolute reduction of $6.9 \mathrm{GtC} / \mathrm{yr}$. On the basis of the relative $\mathrm{CO}_{2}$ emissions summarized in figure 6 , the strongest carbon emission decrease for the Soft landing policy element occurs after the year 2020, when all regions have an obligation to reduce their $\mathrm{CO}_{2}$ emissions. On the other hand, the most significant reductions for the Externality scenario are achieved between 2010 and 2020, and the reduction goes actually beyond the targets of the Soft landing scenario. This early reduction of $\mathrm{CO}_{2}$ emissions results from a substantial fallback of coal-based power generation implicit to the premature retirement of coal plants without $\mathrm{SO}_{2} / \mathrm{NO}_{x}$ control. By the end of the time horizon, the Renewable portfolio and the Externality scenario show similar reductions in carbon emissions, with annual reductions over the Baseline in 2050 of $10.3 \%$ for the former and of $13 \%$ for the latter scenario.

Finally, the $\mathrm{CO}_{2}$ reduction trajectory for the scenario where carbon constraint and external costs are applied in parallel (i.e., the scenario Soft landing + Externalities) documents that in the case of Combined policy scenarios, ancillary benefits and synergies can be expected from policies elements that directly address different sustainability issues: $\mathrm{CO}_{2}$ mitigation and air pollution reduction. This phenomenon of the so-called double environmental dividend, reported in similar studies [27], is related not only to carbon emissions, but also to emissions of $\mathrm{CH}_{4}$, $\mathrm{SO}_{2}$ and $\mathrm{NO}_{x}$. Another synergetic effect is observed in the scenario Renewable portfolio + Externalities, where the carbon emissions decrease is larger in 2040 and 2050 compared to the single policy cases. Two reasons for this result can be identified as: (a) the Renewable portfolio forces a greater penetration of carbon-free supplies based on renewable-energy sources than is achieved by internalising the air pollution damages; (b) the low external cost of nuclear plants increases its competitiveness, and, thereby, the contribution of nuclear power is higher than in the separate adoption of the Renewable portfolio policy.

Figure 7 shows how the carbon reduction associated with different policy options is achieved by plotting baseline-normalized carbon intensity $\left(\mathrm{CO}_{2}\right.$ emitted per unit of primary energy consumed) versus energy intensity based on primary energy (primary energy consumed per unit of GDP produced), all expressed as a function of time. All scenarios tend to achieve the $\mathrm{CO}_{2}$ emission decrease by reduction in carbon intensity. Projections of how the reference energy system reacts to meet respective policy

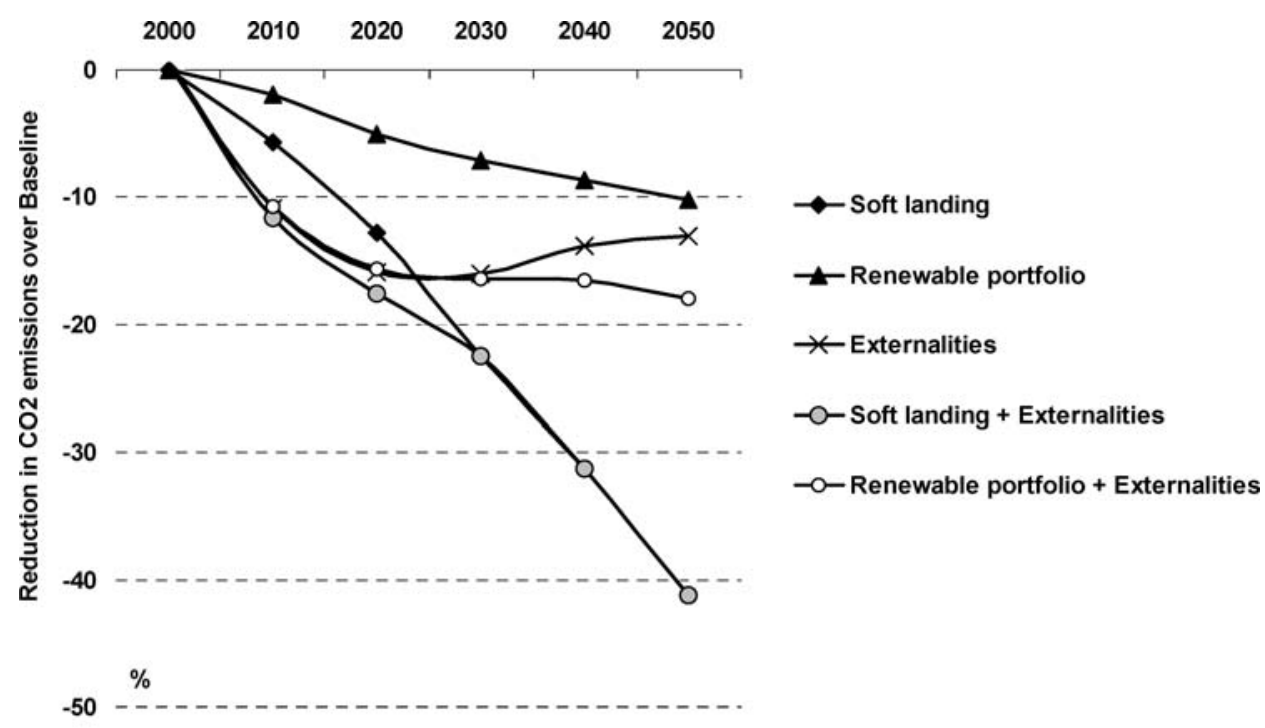

Figure 6. Change in the global carbon emissions relative to the Baseline scenario. 


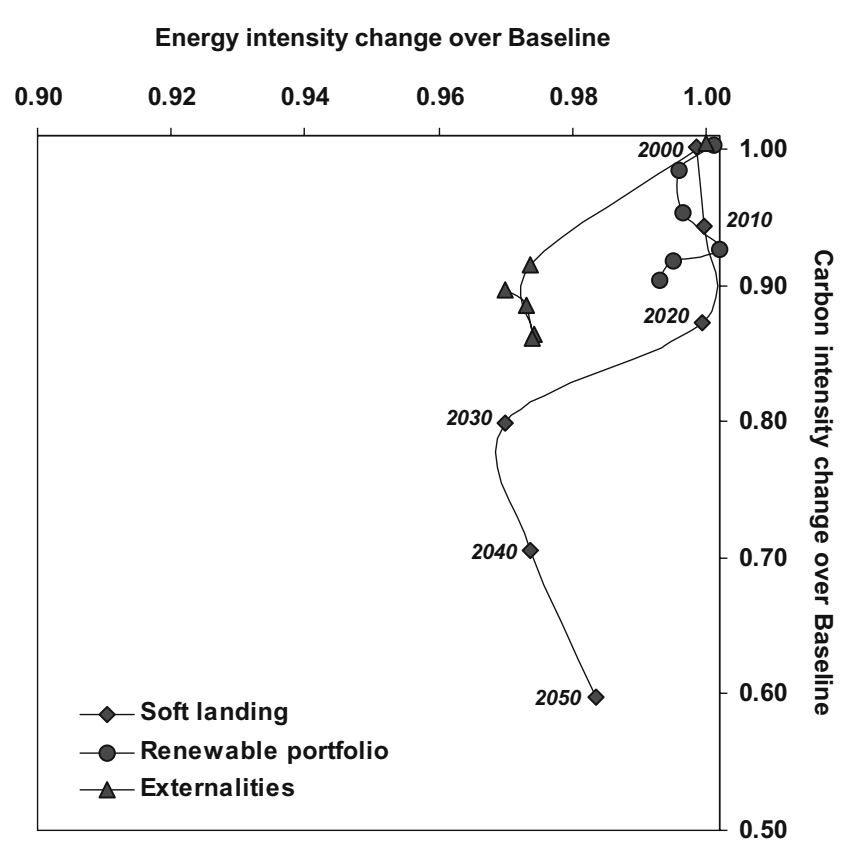

Figure 7. Projection of changes in energy and carbon intensity relative to the Baseline scenario. (Index: Baseline $=1$ ).

goals, however, vary somewhat across scenarios. The strong decarbonisation effect of the Soft landing scenario results in a relative decrease in carbon intensity by $40 \%$ relative to the Baseline, which makes the Soft landing policy scenario the least carbon-intensive, followed by the Externality policy scenario.

In the Soft landing scenario the reduction in energy intensity grows between 2020 and 2030, and becomes lower towards the end of time horizon, while the decrease in energy intensity is most pronounced under conditions of the Externality scenario, where the external cost charges lead to the strongest demand reduction especially for period 2010-2020.

\subsection{Cost impacts}

Policy options analysed in this study suggest varying potentials to reduce carbon emissions at different cost levels. Marginal carbon abatement costs (equal to carbon emission permit prices) are presented in figure 8 for the Soft landing scenario and three Combined policy scenarios where explicit $\mathrm{CO}_{2}$ reduction targets apply. Carbon permit prices vary across scenarios and over time. Differences are determined by (a) the level of severity of carbon constraint relative to the Baseline case in combination with other policy elements, (b) the dynamics of technology change (ETL), and (c) the $\mathrm{CO}_{2}$-permits trade specification.

In all scenarios, the price of carbon permits increases over the time horizon, with the exception of the period around 2020. Reduction in marginal cost during this period is explained by the increased supply of carbon permits originating from non-Annex B countries joining the carbon mitigation regime from 2020 onwards. In 2050, the carbon permit price reaches $145 \$ / \mathrm{tC}$. This price is reduced by $23 \%$ when the Soft landing reduction target is combined with the Renewable portfolio scheme. Similarly, the carbon permit price is lower under the scenario that combines the carbon reduction constraint with the inclusion of external costs associated with local pollution. In addition, the externality-induced rapid elimination of coal-fired conventional power technologies between 2010 and 2020 reduces the $\mathrm{CO}_{2}$ emission level beyond the target specified by Soft landing scenario, which results in zero carbon-permit prices in 2010 and 2020. The price-reducing effects of combining selected policy elements become more pronounced in a scenario where the three policy instruments are simultaneously applied. The significant marginal cost

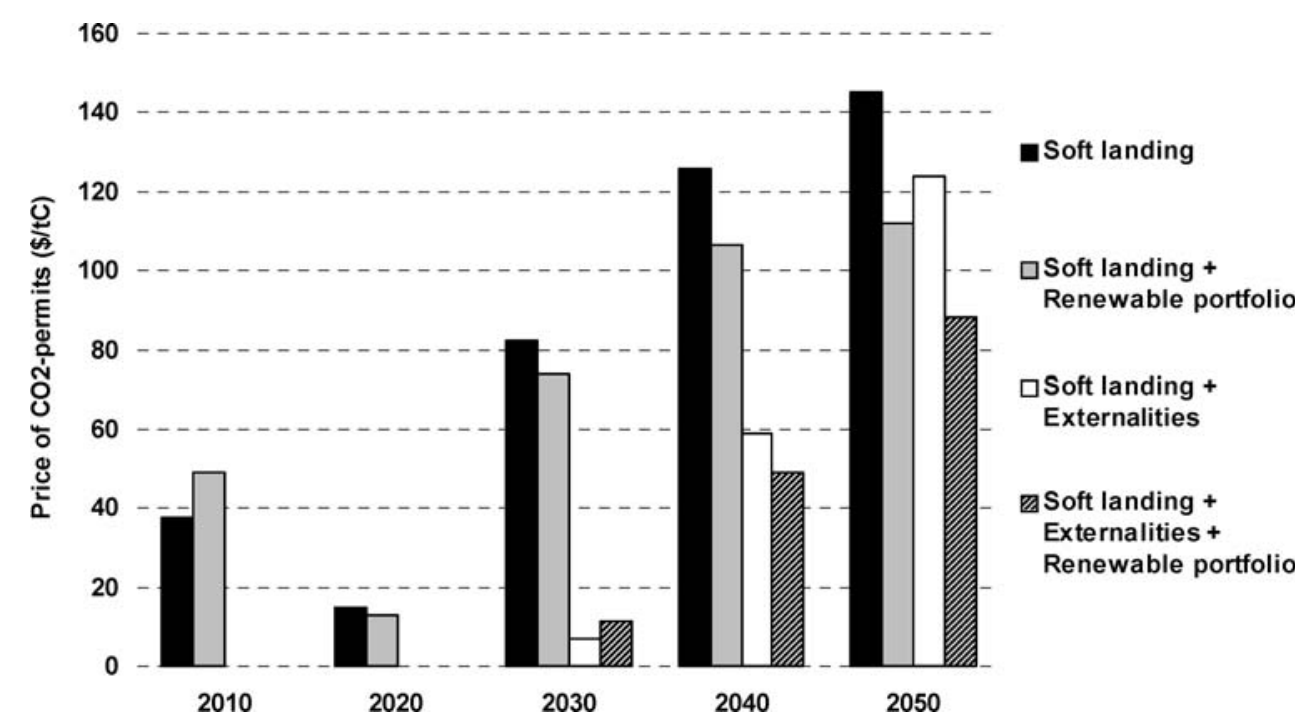

Figure 8. Marginal cost of $\mathrm{CO}_{2}$ emission permits for scenarios combining $\mathrm{CO}_{2}$ reduction with other sustainability objectives. 
reduction in 2040-2050 is attributed to ETL, since the combination of policy elements accelerates the learning performance of carbon-free (or low-carbon) electricity generation technologies (e.g., advanced nuclear plants, renewables, IGCC with carbon capture).

Observations similar to the marginal cost of carbon permits apply for the price of green certificates, which is equal to the marginal cost of green electricity globally traded across world regions, or to the shadow price of renewable electricity constraint defined by the Renewable portfolio scheme, as discussed in section 3. The marginal cost varies in the case of sole policy adoption over the time horizon within a range from 2.6 to $5.2 \mathrm{c} / \mathrm{kWh}$ (figure 9). More important than numerical values is that increased amount of green certificates available for trade in 2020 (from this period onwards the regions with large renewable-energy potentials - ASIA and LAFM - start to implement the policy target) results in price reduction in 2020-2030, as compared to 2010. When the Renewable portfolio scheme is combined with carbon constraint and the external cost policies, the fraction of renewable electricity generated in 2010-2020 exceeds the fractional target prescribed under single-policy conditions; marginal costs for this time segment, therefore, are zero. Decreases in price of green certificates in 2040-2050, relative to the separate policy implementation, is - again - a consequence of LBD cost-reducing effects.

Figure 10 displays the relative changes of the total discounted energy system costs and the welfare loss due to demand reductions (i.e., objective function used in GMM) for the policy options analysed as compared to the Baseline scenario. Variations in the value of the objective function reflect the level of cost effectiveness of respective policy scenarios and a (economic) severity of constraints imposed. The discounted energy system cost together with the welfare loss (sum of consumers and producers surpluses) is increased by $1.6 \%$ in the Soft landing scenario, where the carbon mitigation constraint is applied on the entire energy system. The Renewable portfolio scheme has been formulated in a way where it emerges as the least-cost singlepolicy option $(1.2 \%$ increase in total cost relative to the Baseline), which is explained by the fact that the constraint is mainly affecting the electricity sector alone. Externality scenario is the most expensive of single-policy elements primarily because of premature closure of existing conventional coal power plants and the costs associated with rapid technology and inter-fossil fuel switching. The total cost increase over the Baseline case for the Externality scenario amounts to $10 \%$. As is indicated in figure 10 , the contribution of the external cost itself counts for around $80 \%$ of the total cost increase, while the reminder is attributed to the structural changes and fuel switching occurring within the energy system.

Potential trade-offs and co-benefits resulting from simultaneous application of policy options become relevant again, when increase in total discounted energy system cost and welfare losses for the separate implementation of policy elements are added together and compared with the modelling results from the Combined policy scenarios. Increase in the objective function for the set of combined policies is $15-30 \%$ lower than the sum of increases in three single-policy scenarios considered in this study. This finding illustrates the existence of synergies between the policy instruments considered here and suggests that a double dividend associated with pursuing different sustainability objectives can be considerably large. Hourcade et al. [27] indicates the aggregate cost savings by $40 \%$ resulting from simultaneous reduction of $\mathrm{CO}_{2}$ and $\mathrm{SO}_{2}$ emissions, especially for the Asia region, but this effect can occur only if sufficient resources will be transferred interregionally through, for example, the Kyoto-like flexible mechanisms.

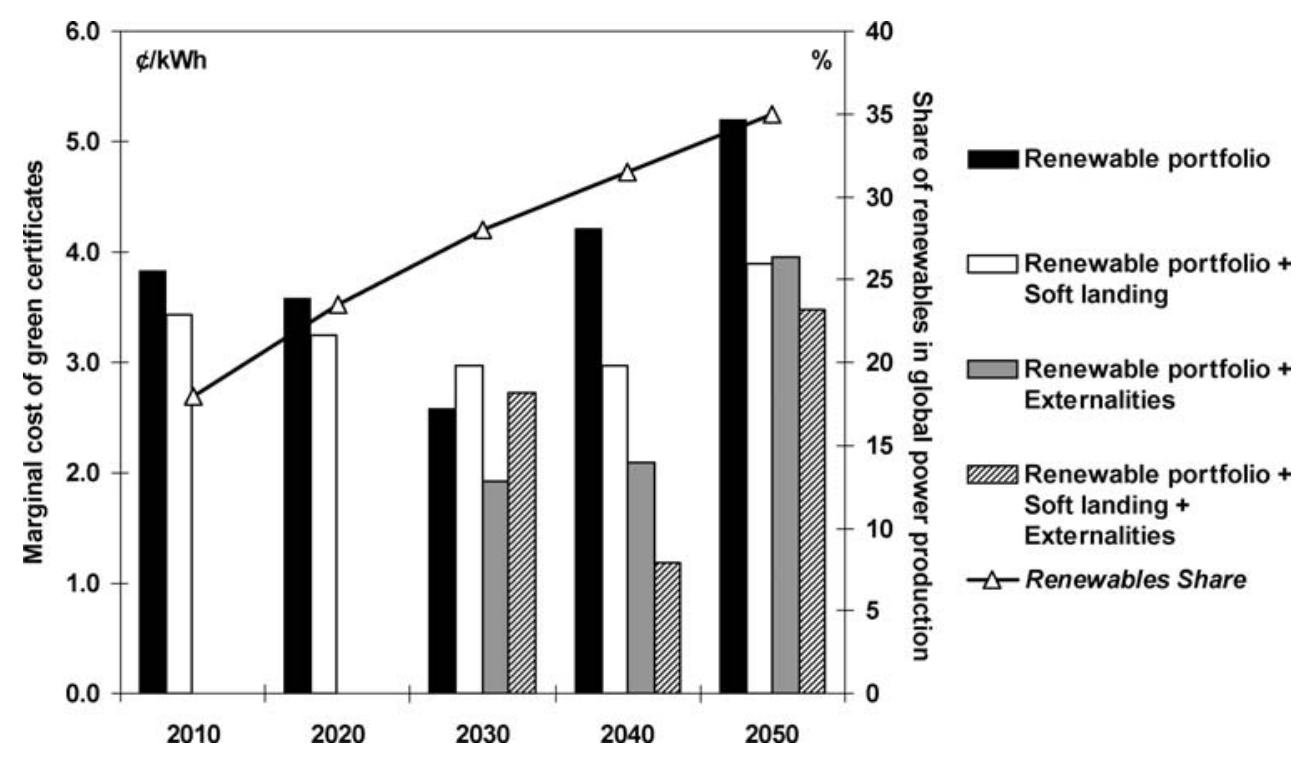

Figure 9. Marginal cost of green electricity certificates in selected scenarios. 


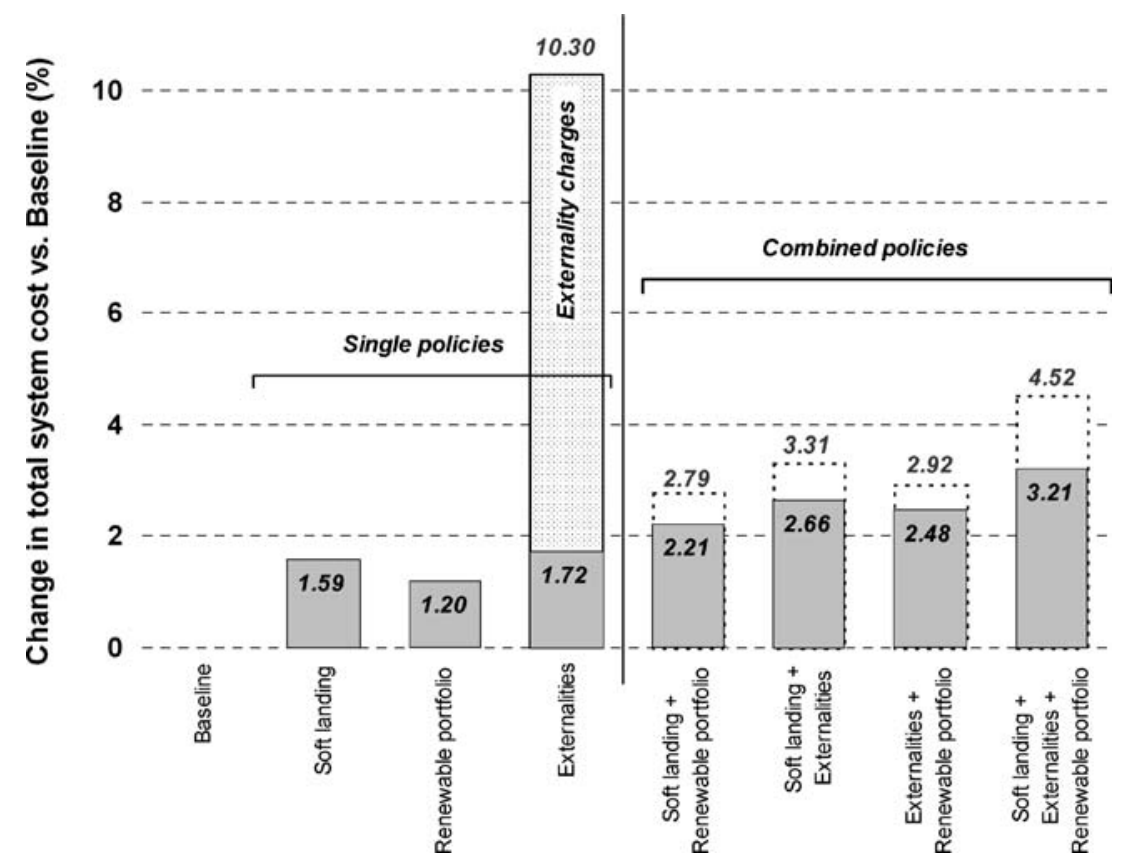

Figure 10. Change in cumulative discounted energy system cost relative to the Baseline scenario associated with the structural changes within the global energy system and with the external cost charged in the Externality scenario. Dotted bars represent the sum of relative increases in total costs for singlepolicy scenarios.

As discussed in the previous sections, effective implementation of sustainable-energy policies largely depends on political circumstances that stimulate deployment of advanced, less carbon-intensive technologies, and allows for market-oriented flexibility mechanisms helping in overall cost reduction. An example is given in figure 11, which elucidates potential impacts of different policy modalities in achieving the Soft landing emission-reduction targets. Relative increases in the discounted energy system cost in the case of a cumulative carbon constraint enforced in conjunction with active ETL and trade options is reduced by $15 \%$ as compared to the Soft landing scenario with fixed annual reduction bounds. This result indicates the benefits of less-stringent timing of achieving the carbon-mitigation burden (i.e., "when" flexibility). Contrarily, if the reduction entitlements defined by the Soft landing scenario are applied without the possibility to trade carbon permits, the total system cost is increased by $47 \%$ relative to the policy allowing for carbon-permit trade among world regions.

Furthermore, the presented results suggest that policies helping the advanced technologies to follow the re-

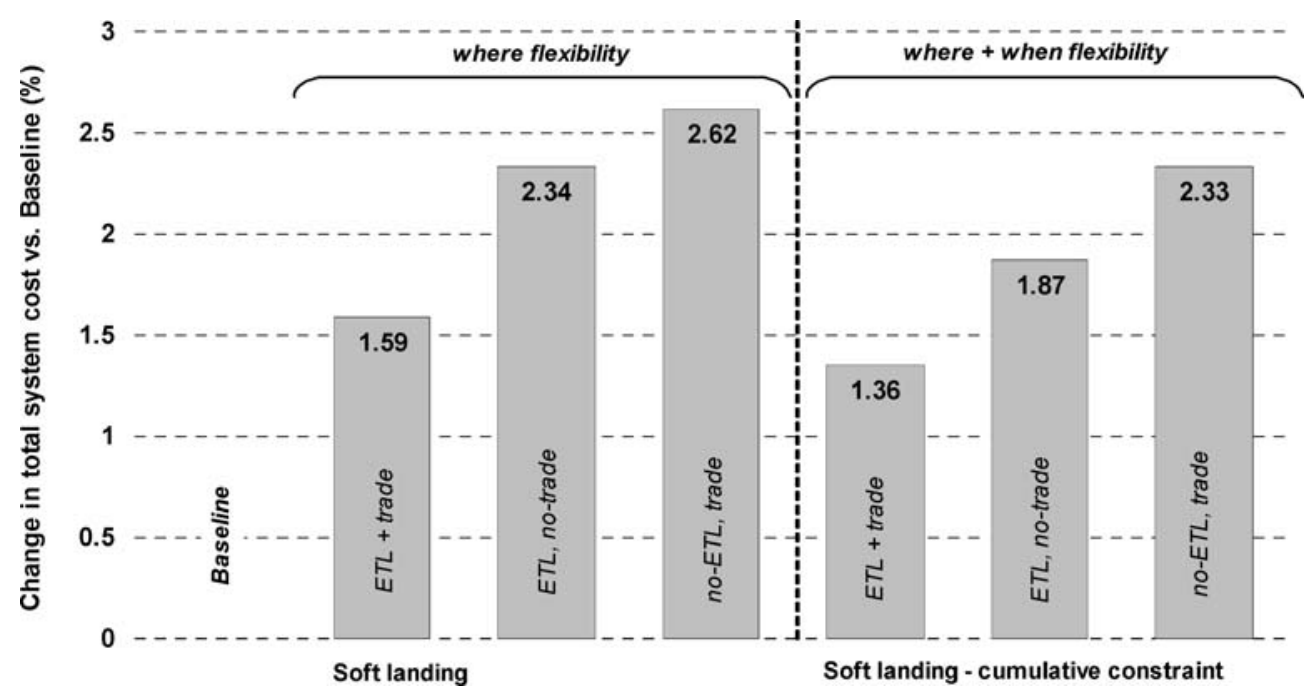

Figure 11. Relative change in the cumulative discounted energy system cost over the Baseline for different modalities of the Soft landing scenario. 
Table 8

Impacts of selected parameters on the cost indicators for the single policy scenarios.

\begin{tabular}{|c|c|c|c|c|c|c|c|}
\hline & \multicolumn{2}{|c|}{ Scenario } & \multicolumn{2}{|c|}{ Soft landing } & \multicolumn{2}{|c|}{ Renewable portfolio } & \multirow{2}{*}{$\begin{array}{c}\text { Externalities } \\
\text { Total cost } \\
\text { increase, } \%\end{array}$} \\
\hline & \multicolumn{2}{|c|}{ Cost indicators } & \multirow{2}{*}{$\begin{array}{c}\text { Total cost } \\
\text { increase, } \% \\
1.6\end{array}$} & \multirow{2}{*}{$\begin{array}{c}\text { Cost of C-permits } \\
(2050), \$ / \mathrm{tC} \\
145.2\end{array}$} & \multirow{2}{*}{$\begin{array}{c}\text { Total cost } \\
\text { increase, } \% \\
1.2\end{array}$} & \multirow{2}{*}{$\begin{array}{c}\begin{array}{c}\text { Cost of green } \\
\text { certif. }(2050), \\
\phi / \mathrm{kWh}\end{array} \\
5.2\end{array}$} & \\
\hline & Original case & $\begin{array}{c}d=5 \%, \text { ETL } \\
\text { Trade }\end{array}$ & & & & & 1.7 \\
\hline \multirow{6}{*}{$\begin{array}{l}\text { Sensitivity } \\
\text { parameters }\end{array}$} & Changed policy & $+10 \%$ & 1.9 & 168.0 & - & - & - \\
\hline & target & $+5 \%$ & - & - & 1.6 & 6.2 & - \\
\hline & Discount rate & $d=3 \%$ & 1.8 & 109.6 & 1.3 & 3.3 & 1.6 \\
\hline & & $d=7 \%$ & 1.5 & 197.6 & 0.8 & 8.5 & 2.3 \\
\hline & Policy set-up & No-ETL & 2.6 & 153.3 & 2.1 & 7.0 & - \\
\hline & & No-Trade & 2.3 & - & 2.1 & - & - \\
\hline
\end{tabular}

spective learning curves (ETL) can moderate cost penalty associated with implementation of climate response measures by $40 \%$. Still, although models based on perfect-foresight algorithms, such as GMM, indicate that carbon-free systems will become competitive in the long term; this expectation is probably not realistic for the conditions under which "real-world" markets operate. Solar photovoltaic or $\mathrm{H}_{2}$-driven fuel-cell systems at the present stage of development are expensive compared to conventional fossil fuel systems. Policies favouring the introduction of these advanced technologies are necessary for their establishment in the markets to an extent where technical progress along the respective learning curves and the attendant reduction in specific (unit) costs can occur [4].

\subsection{Robustness of the results}

Each of the policy instruments examined in this work has been tested by additional sensitivity scenarios to provide insights into the robustness of the modelling outcomes. A sensitivity analysis of the impacts of three selected parameters - a modified policy target, the discount rate, and the policy set-up - is carried out in this section. For the Soft landing scenario the mitigation target has been increased by $10 \%$, and for the Renewable portfolio
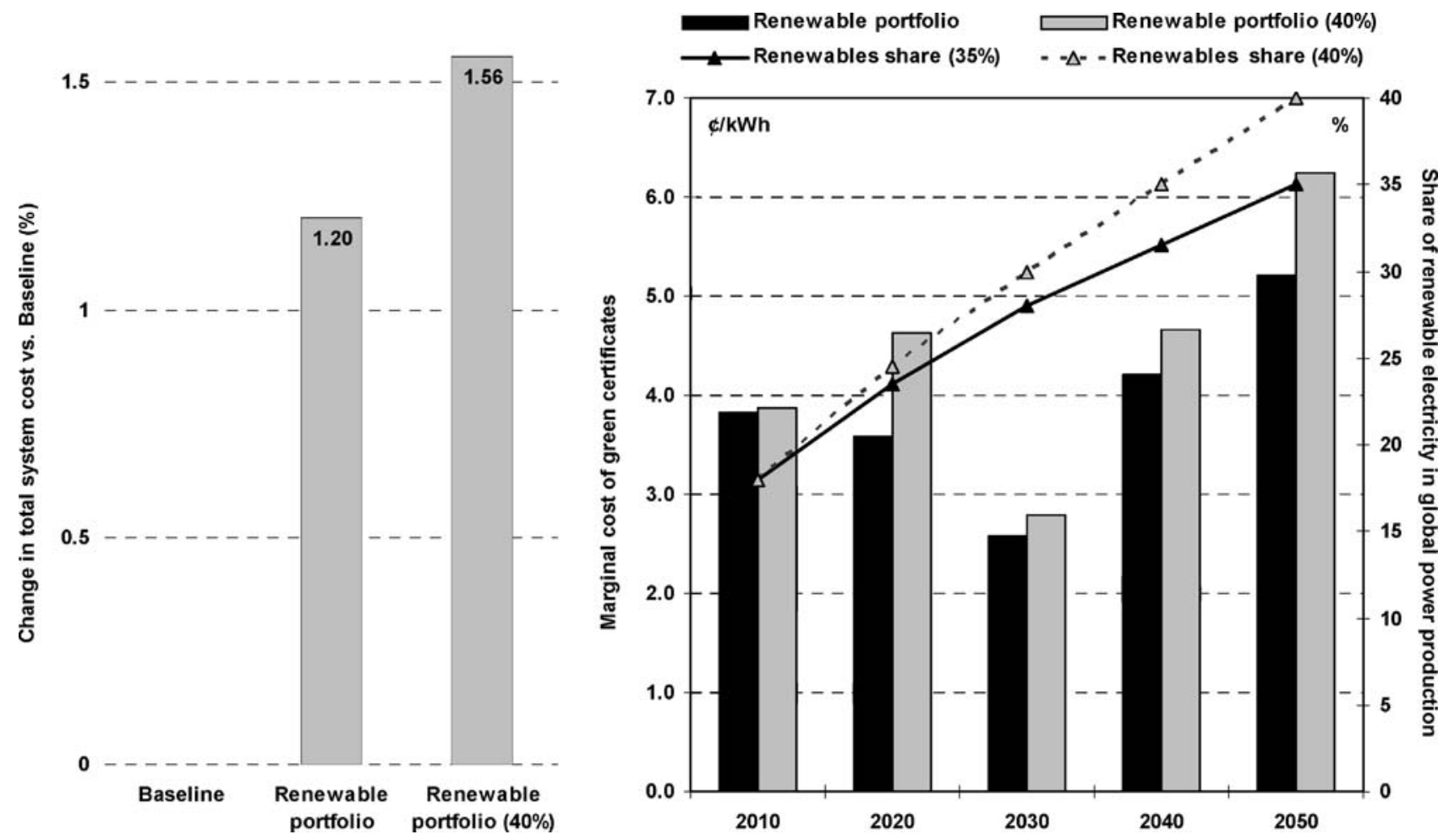

Figure 12. Sensitivity of the cost indicators for the Renewable portfolio scenario to the increase of the policy target. 
scenario the fractional target for renewable electricity has been increased by $5 \%$ in 2050 . As summarised in table 8 , for both scenarios an increase in the total system cost over the Baseline by $20-30 \%$ emerged. From the results, however, it is interesting to note that increases in total system cost due to elimination of trading of carbon permits or green certificates, as well as due to the absence of ETL option, are actually higher than in the scenarios forcing more stringent policy constraints.

The increases in total system cost and the marginal cost of green certificates for the 35 and $40 \%$ fractional target of the Renewable portfolio policy are compared in figure 12 . The cost of green electricity is $1-30 \%$ higher in $2010-2050$ for the $40 \%$ green electricity target. At the same time, this increase is lower compared to the $35 \%$ target with the ETL option inactive.

Two additional sensitivity cases are reported here for three single policy scenarios, using the discount rate of 3 and $7 \%$ (see table 8 ). For the Soft landing and Renewable portfolio scenarios, the $3 \%$ discounting results in a total cost that is higher than in the cases with the discount rate of 5 and $7 \%$. These changes are associated with the discounting procedure applied to the objective function in GMM, as explained by Loulou et al. [13]. In contrast, the technology-related discounted cost increases with the higher discount rate for the Externality scenario. This finding is explained by the fact that the stringency of the Externality case is higher in the initial stages of policy application (e.g., 2010-2020) compared to the later phases. This result also suggests that the policy constraints adopted in the Soft landing and Renewable portfolio scenarios are more gradual, with the larger cost impacts towards the end of the computational period. Sensitivity of the modelling results to other parameters (e.g., the learning rate, annual growth rates, etc.) can be found in the report of Rafaj [29].

\section{Conclusions}

Addressing issues related to sustainable development of the global energy system requires appropriate policy actions while taking into consideration the economic, environmental and social circumstances in different world regions. Formulation and evaluation of policy measures has been a substantial research effort over the past decades. Most of the analyses, however, assess the policy impacts of single policy elements, which are often driven by the differences in preferences and priorities of the market players. Nevertheless, the complexities of crosscutting issues inherent to the sustainable energy supply and use call for exploration of a broader interconnected policy framework.

In this paper, a set of three selected policy instruments addressing different aspects of sustainability in the global energy system has been examined: a $\mathrm{CO}_{2}$ emission reduction target - "Soft landing" scenario, a renewable portfolio standard, and internalisation of external costs for air pollutants from electricity generation. Additionally, several combined policies where the policy elements or options are applied simultaneously are investigated (Soft landing + Renewable portfolio, Soft landing + External Costs, Renewable portfolio + External Costs, Soft landing + Renewable portfolio + External Costs). Impact assessment of policy instruments is an important component of the policymaking process. Moreover, examining the effects of combining policy instruments may provide policymakers with insights into potential synergies and/or trade-offs between different policy objectives, which cannot be dealt with in isolation.

Results presented in this study depend on the particular baseline scenario adopted as a reference point of departure, as well as on specific assumptions made about energy technology dynamics. Insights derived from this model exercise, however, illustrate the benefits that the set of single and combined air-emission mitigation strategies might offer. A portfolio of win-win policies based on the support of new technologies, cap-and-trade actions for mitigation of carbon emissions in combination with a realistic renewable portfolio scheme and with policies that internalise external cost incurred from energy production, might together form key constituents of a road map pointing towards a sustainable global energy system. These combined policies also result in reduced dependency on fossil-fuel supplies, and in a more resilient energy and social system with improved local and global environments.

Based on the analyses of the policy options investigated, the following specific conclusions in favour of more sustainable global energy-system developments are identified.

The Soft landing scenario stabilises global $\mathrm{CO}_{2}$ emissions to levels below $10 \mathrm{GtC} / \mathrm{yr}$ by 2050 at total system cost $1.6 \%$ higher than the Baseline scenario. Marginal abatement costs increase over the time horizon and reach a level of $145 \$ / \mathrm{tC}$ in 2050. International trading of $\mathrm{CO}_{2}$ emissions permits (or the "where" flexibility) benefits from efficient $\mathrm{CO}_{2}$ abatement options across the world and contributes to a significant reduction in carbon control cost. Optimal timing (or the "when" flexibility) identifies a costoptimal path in imposed $\mathrm{CO}_{2}$ reduction targets and can produce additional gains of $15 \%$ in the total system cost as compared to the "where" flexibility policy option. A carbon mitigation target, as defined in this study, induces important shifts in the energy system towards less carbonintensive technologies and fuels (nuclear energy, renewables). Advanced coal-based systems equipped with $\mathrm{CO}_{2}$ capture penetrate the electricity market and play an important role in carbon abatement.

The Renewable portfolio scheme, as modelled in this study, represents a cap-and-trade policy that forces electricity generation from renewable-energy sources to reach a global level of $35 \%$ by 2050 . The associated increase in the total cost is computed to be $1.2 \%$ relative to the Baseline development. The most significant increase in generation 
from renewable-energy sources is reported for biomass technologies, geothermal plants and hydroelectric power. At the end of the time horizon, SPV systems are introduced into the power generation mix at a considerable level. An important observation is that market-oriented policies favouring the trade of green certificates across all world regions identifies the most efficient locations to install renewable-energy systems and moderate the induced cost impacts. The price of green certificates resulting from the constraint applied is competitive when compared to the present costs for electricity generation. A prerequisite to successful implementation of this policy instrument is the need to convince market actors to invest in renewable-energy technologies for the initial period of their market penetration when the new systems are not competitive.

Internalisation of external cost associated with local pollution emerges as the most expensive policy among the single-policy elements analysed. Substantial changes in the electricity production system and rapid fuel switching take place especially during the period 2010-2020. Conventional coal-fired power plants are eliminated and replaced by advanced plants with emission control. Natural gas combined cycles, nuclear power and renewables increase their share in the power generation mix. The inclusion of external costs in the price of electricity has positive global and local environmental impacts related to reductions in local emissions and a significant decarbonisation effect. To facilitate further sustainable development in the energy sector, this policy instrument can be improved through appropriate cost pricing applied not only for electricity, but also for other fossil fuels, in a way that accounts for both local $\left(\mathrm{SO}_{2}, \mathrm{NO}_{x}, \mathrm{PM}\right)$ and global $\left(\mathrm{CO}_{2}, \mathrm{CH}_{4}, \mathrm{~N}_{2} \mathrm{O}\right)$ externalities.

The modelling results indicate that a range of potential synergies and ancillary benefits might result by joint application of the different policy elements considered separately in this study. For example, internalisation of external cost from local pollution can contribute to the achievement of more ambitious carbon emission reduction targets as defined by the Soft landing scenario at a cost level that is lower than the costs resulting from separate adoption of both policies. According to Hourcade et al. [27], occurrence of this environmental double dividend requires interregional transfer of financial resources for investments in advanced energy technologies and may indirectly help in preventing the developing regions of Asia to remain "locked-in" coal-based energy systems.

Significant structural changes can occur on both the supply and demand sides of the energy system when stringent carbon and local pollution mitigation policies are implemented. On the supply side, the fossil-fuel-based systems are the most affected. To avoid excessive costs resulting from the imposition of respective policy targets, the power generation mix will have to consist of a portfolio of robust technology options. The technology portfolio that emerges from this analysis is composed of natural gas combined cycle units, nuclear power plants, advanced coal power plants equipped with $\mathrm{SO}_{2} / \mathrm{NO}_{x}$ scrubbers and $\mathrm{CO}_{2}$ capture systems. Among renewable-energy systems represented in GMM, wind, hydropower and biomass plants can play an important role in meeting specific sustainability goals.

On the end-user side of the market, it is expected that carbon mitigation policies imposed will increase the price of electricity and fossil fuels; therefore, a reduction in final demand together with fuel substitution is expected to occur. Although the end-use demand reductions are not reported in detail in this study, related contribution to the carbon abatement targets and the decreasing dependency on fossil fuels is important.

\section{List of acronyms}

$\not$

$\$$

ACROPOLIS

Cent $\left(10^{-2} \$\right)$

US dollar

ANNEX B

Assessing Climate Response Options: Policy Simulation project

ANNEX B List of countries with reduction targets

ASIA Centrally Planned Asia, India, Southeast and Pacific Asia

B2 "Dynamics-as-usual" family of scenarios defined by SRES

C Carbon

capt $\quad \mathrm{CO}_{2}$ capture

$\mathrm{CH}_{4} \quad$ Methane

$\mathrm{CO}_{2} \quad$ Carbon Dioxide

d Discount rate

$\operatorname{DeNO}_{x} \quad$ Nitrogen oxides abatement,

denitrification

$\mathrm{DeSO}_{x} \quad$ Sulphur oxides abatement,

EC desulphurisation

EC European Commission

EEFSU Eastern Europe and Former Soviet

Union

ETL Endogenous technological learning

EU European Union

ExternE Externalities of Energy

FC Fuel cell

GDP

GHG

GMM

IEA

IGCC

Gross domestic product $(\mathrm{T} \$ / \mathrm{yr})$

Greenhouse gas

Global Multi-regional Markal model

International Energy Agency

Integrated coal gasification combined

cycle

IPCC Intergovernmental panel on climate change

J Joule

LAFM Latin America, Africa, and Middle East region

LBD Learning-by-doing

LR Learning rate 


\begin{tabular}{|c|c|}
\hline LWR & Light water reactor \\
\hline MARKAL & Market allocation model \\
\hline n.a. & Not applicable \\
\hline NAME & North American region \\
\hline NCCR & $\begin{array}{l}\text { National Centre of Competence in } \\
\text { Research }\end{array}$ \\
\hline NGCC & Natural gas combined cycle \\
\hline NNU & New (design of) nuclear power plant \\
\hline $\mathrm{N}_{2} \mathrm{O}$ & Nitrous oxide \\
\hline $\mathrm{NO}_{x}$ & Nitrogen oxides \\
\hline O\&M & Operation and maintenance \\
\hline OECD & $\begin{array}{l}\text { Organization for Economic Cooperation } \\
\text { and Development }\end{array}$ \\
\hline OOECD & $\begin{array}{l}\text { Other OECD region: Western Europe, } \\
\text { Japan, Australia, and New Zealand }\end{array}$ \\
\hline PFBC & Pressurised fluidised bed combustion \\
\hline PM & Particulate matter \\
\hline ppmv & Parts per million by volume \\
\hline $\mathrm{pr}$ & Progress ratio \\
\hline PSI & Paul Scherrer Institut \\
\hline RES & Reference energy system \\
\hline $\mathrm{SO}_{2}$ & Sulphur dioxide \\
\hline SPV & Solar photovoltaic system \\
\hline SRES & Special report on emission scenarios \\
\hline $\mathrm{t}$ & Tons, metric tonnes $\left(10^{3} \mathrm{~kg}\right)$ \\
\hline $\mathrm{tC}$ & Tonnes carbon \\
\hline $\mathrm{tCO}_{2}$ & Tonnes carbon dioxide \\
\hline UNDP & $\begin{array}{l}\text { United Nations Development } \\
\text { Programme }\end{array}$ \\
\hline UNFCCC & $\begin{array}{l}\text { United Nations Framework Convention } \\
\text { on Climate Change }\end{array}$ \\
\hline USA & United States of America \\
\hline US DOE & United States Department of Energy \\
\hline W & Watt \\
\hline Wh & Watt-hour \\
\hline
\end{tabular}

\section{Acknowledgements}

The authors would like to thank Prof. A. Wokaun and Dr. R. Krakowski from the General Energy Department of Paul Scherrer Institute, as well as two unknown EMA referees for comments and suggestions that helped to improve the presentation of this analysis. The support of the Swiss National Science Foundation in the context of the NCCR-Climate project and the Swiss Office for Science and Education for the EU-ACROPOLIS project is gratefully acknowledged.

\section{Appendix: Policy formulation in the GMM model}

\section{Carbon abatement - Soft landing scenario}

The amount of regional $\mathrm{CO}_{2}$ emissions (minus sequestration Seq) should be below a fractional reduction (fr) of the reference emissions (REF) by region $(r)$ and time $(t)$ such that a reduction target is fulfilled. The $\mathrm{CO}_{2}$ balance is made considering the primary-energy use of fossil fuels (fossil $\left.l_{r, f f, t}\right)$ and their specific emission coefficients $\left(\mathrm{SE}_{f f}\right)$, while sequestration options for electricity generation technology $(j)$ are associated with negative emission coefficients per unit of electricity (ELE) produced.

$$
\begin{aligned}
\sum_{r, f f} \text { fossil }_{r, f f, t}^{\mathrm{Soft}} \cdot \mathrm{SE}_{f f}-\sum_{j \in \mathrm{Seq}} \mathrm{ELE}_{j} \cdot S E_{j} \\
\leq\left(1-\mathrm{fr}_{r, t}\right) \cdot \sum_{r, f f} \text { fossil }_{r, f f, t}^{\mathrm{REF}} \cdot \mathrm{SE}_{f f}
\end{aligned}
$$

Since the constraint is applied at the global level, trade of emission permits is allowed.

\section{Renewable portfolio scheme}

The relative share of renewable-energy systems (ren) in the regional $(r)$ production of electricity (ELE) should be above a given fraction $\left(\mathrm{fr}_{r}\right)$ of total electricity generation from all technologies (all). As this constraint is applied on the global level, trade of green certificates is possible.

$$
\sum_{r, \text { ren }} \mathrm{ELE}_{r, \text { ren }} \geq \sum_{r} \mathrm{fr}_{r} \sum_{\text {all }} \mathrm{ELE}_{r, \text { all }}
$$

\section{Internalisation of externalities}

External costs (EXT) are implemented by multiplying the amount (ELE) of electric power generated (i.e., $\mathrm{kWh}$ ) from each power plant $(j)$ during each time period $(t)$ in each region $(r)$ with corresponding external cost (i.e., $ф / \mathrm{kWh})$. In this way, it is assured that the matching external costs are directly charged to every unit of output from each power plant. The sum of discounted annual externality charges for every region is reflected in the total discounted system $\operatorname{cost} Z$ (i.e., the objective function used in GMM) in the externality case (extern):

$$
Z_{\text {extern }}=Z+\sum_{t} \mathrm{EXT}_{t} \cdot y p p \cdot Q_{t} \cdot(1+d)^{-t}
$$

where $Q_{t}$ stands for the total quantity of electricity generated by all technologies, ypp are the years per period $t$, and $d$ is the discount rate.

\section{Endogenous learning by doing}

The specific costs $S C_{j t}$ of technology (j) can be reduced due to the accumulation of experience approximated by the term $\left[\frac{C C_{j t}}{C C_{j 0}}\right]^{-\beta_{j}} ; \beta_{j}$ is the learning index and $C C$ is cumulative capacity.

$$
\begin{aligned}
\mathrm{SC}_{j t} & =\mathrm{SC}_{j 0}\left[\frac{C C_{j t}}{C C_{j 0}}\right]^{-\beta_{j}}, \text { where } \\
\beta_{j} & =\frac{\ln \left(1-\mathrm{LR}_{j}\right)}{\ln 2} \text { and } \mathrm{LR}_{j} \text { is the learning rate. }
\end{aligned}
$$




\section{References}

[1] IEA (International Energy Agency), Towards a Sustainable Energy Future (International Energy Agency (IEA), Paris, France, 2001).

[2] L. Schrattenholzer, A. Miketa, K. Riahi, R. Roehrl, B. Zhu, G. Totschnig and M. Strubegger, Achieving a sustainable global energy system, in: ESRI Studies Series on the Environment (Edward Elgar, Cheltenham, United Kingdom, 2004)

[3] EC (European Commission), Communication from the Commission on Impact Assessment (Document COM(2002) 276 Final, European Commission, Brussels, Belgium, 2002).

[4] IEA (International Energy Agency), Creating Markets for Energy Technologies (International Energy Agency (IEA), Paris, France, 2003).

[5] N. Beg, J.C. Morlot, O. Davidson, Y. Afrane-Okesse, L. Tyani, F. Denton, Y. Sokona, J.P. Thomas, E. Lèbre La Rovere, J.K. Parikh, K. Parikh and A. Rahman, Linkages between climate change and sustainable development, Climate Policy 77 (2002) 1-16.

[6] L. Barreto, Technological Learning in Energy Optimisation Models and Deployment of Emerging Technologies, $\mathrm{PhD}$ dissertation No. 14151, ETH, Zurich, Switzerland (2001).

[7] L. Barreto and S. Kypreos, Emissions trading and technology deployment in an energy-systems "Bottom-Up" model with technology learning, Eur. J. Oper. Res. 158 (2004) 243-261.

[8] P. Rafaj, S. Kypreos and L. Barreto, Flexible carbon mitigation policies: Analysis with a global multi-regional MARKAL model, in: Coupling Climate and Economic Dynamics, eds. A. Haurie and L. Viguier (Springer, Dordrecht, the Netherlands, 2005).

[9] L.G. Fishbone and H. Abilock, MARKAL, a linear-programming model for energy systems analysis: Technical description of the BNL version, Int. J. Energy Res. 5 (1981) 353-375.

[10] IPCC (Intergovernmental Panel on Climate Change), Special Report on Emission Scenarios, A Special Report of the Working Group III of Intergovernmental Panel on Climate Change (Cambridge University Press, Cambridge, UK, 2000).

[11] K. Riahi and R.A. Roehrl, Greenhouse gas emissions in a dynamicsas-usual scenario of economic and energy development, Technological Forecasting and Social Change 63(2-3) (2000) 175-205.

[12] L. Barreto and S. Kypreos, Multi-regional technological learning in the energy-systems MARKAL model, Int. J. Glob Energy Issues 17(3) (2002) 189-213.

[13] R. Loulou, G. Goldstein and K. Noble, Documentation for the MARKAL Family of Models, Energy Technology Systems Analysis Programme (ETSAP)/IEA (2004) (http://www.etsap.org/tools.htm).

[14] S. Messner, Endogenised technological learning in an energy systems model, J. Evol. Econ. 7 (1997) 291-313.

[15] A. McDonald and L. Schrattenholzer, Learning rates for energy technologies, Energy Policy 29(4) (2001) 255-261.

[16] R. Loulou and D. Lavigne, MARKAL model with elastic demands: Application to greenhouse gas emission control, in: Operations Research and Environmental Management, eds. C. Carraro and A.
Haurie (Kluwer Academic Publishers, The Netherlands 1996) pp. 201-220.

[17] A. Kanudia and R. Loulou, Advanced bottom-up modelling for national and regional energy planning in response to climate change, Int. J. Environ. Pollut. 12(2-3) (1999) 191-216.

[18] UNFCCC (United Nations Framework Convention on Climate Change), The Kyoto Protocol to the Convention on Climate Change, UNFCCC Climate Change Secretariat and UNEP, UNEP/IUC/99/10, Geneva, Switzerland (1999).

[19] EC (European Commission), ExternE - Externalities of Energy, JOULE III Non-Nuclear-Energy Programme, ExternE Final Report (1998) (see also: http://externe.jrc.es).

[20] T.M.L. Wigley, R. Richels and J.A. Edmonds, Economic and environmental choices in the stabilization of atmospheric $\mathrm{CO}_{2}$ concentrations, Nature 379 (1996) 240-243.

[21] O. Blanchard, P. Criqui, A. Kitous and L. Viguier, Combining efficiency with equity: A pragmatic approach, in: Providing Global Public Goods: Managing Globalization, eds. I. Kaul, P. Conceição, K. Le Goulven and R.U. Mendoza (Oxford University Press, New York, 2003).

[22] G.J. Schaeffer, M.G. Boots, J.W. Martens and M.H. Voogt, Tradable green certificates: a new market-based incentive scheme for renewable energy: Introduction and analysis, Report ECN-I-99004, Petten, The Netherlands (1999).

[23] UNDP (United Nations Development Programme), World energy assessment: Energy and the challenge of sustainability, United Nations Development Programme, United Nations Department of Economic and Social Affairs, World Energy Council, ed. J. Goldemberg (New York, USA, 2000).

[24] ACROPOLIS (Assessing Climate Response Options: POLIcy Simulations), Final report April 2001-September 2003, Prepared by IER Germany and IPTS-JRC Spain, Contract No: ENK6-CT2000-00443, Framework Programme V (2003).

[25] GeoHive, Global Statistics, Electronic database of global statistical information maintained by J. van der Heyden (2003) (see also: http://www.geohive.com).

[26] W. Hinrichs, Stoffmengenflüsse und Energiebedarf bei der Gewinnung ausgewählter mineralischer Rohstoffe, Teilstudie Steinkohle, Reihe H, Wirtschaftsgeologie, Berichte zur Rohstoffwirtschaft, Heft SH 4, Geologisches Jahrbuch, Bundesanstalt für Geowissenschaften und Rohstoffe, Hannover, Germany (1999).

[27] J.-C. Hourcade, M. Haduong, A. Gruebler and R.S.J. Tol, INASUD project findings on integrated assessment of climate policies, Integrated Assessment 2(1) (2001) 31-35.

[28] A. Miketa and L. Schrattenholzer, Equity implications of two burden-sharing rules for stabilizing greenhouse-gas concentrations, Energy Policy, in press, Available online 8 October 2004.

[29] P. Rafaj, Analysis of Policies Contributing to Sustainability of the Global Energy System Using the Global Multi-regional Markal Model (GMM), PhD Dissertation No 16122, ETH, Zurich, Switzerland (2005). 